\title{
DYNAMIC RELIABILITY ANALYSIS OF THE REACTOR BUILDING OF A NUCLEAR POWER PLANT FOR ACCOUNTING OF ITS AGING AND DEGRADATION
}

\author{
Di Maio Francesco ${ }^{1}$, Fumagalli Matteo ${ }^{1}$, Guerini Carlo $^{2}$, Perotti Federico ${ }^{2}$, Zio Enrico ${ }^{1,3}$ \\ ${ }^{1}$ Energy Department, Politecnico di Milano, Via La Masa 34, 20156 Milano, Italy \\ ${ }^{2}$ Department of Civil and Environmental Engineering, Politecnico di Milano, Milano, Italy \\ ${ }^{3}$ MINES ParisTech, PSL Research University, CRC, Sophia Antipolis, France
}

\begin{abstract}
The ultimate barrier to prevent contamination of the environment due to a release of radioactivity from a Nuclear Power Plant (NPP) is the reinforced concrete (RC) Reactor Building (RB) which encloses the nuclear reactor. The integrity of this barrier is the main focus of Probabilistic Risk Assessment (PRA)-Level 2, in which accident scenarios that might affect this barrier are modeled in terms of their consequences and their probabilities of occurrence. Traditionally, aging and degradation of the RB are not explicitly considered in the modeling. In this paper, a dynamic reliability approach is adopted to explicitly model aging and degradation, and the effects on the RB resistance to the accidental stresses and eventually its failure probability. A Finite Element Model (FEM) of the RC is developed and coupled with a degradation model. By this, risk measures, like the Large Early Release Frequency (LERF) and its increase in time due to aging ( $\triangle$ LERF), are actualized on the basis of the condition monitoring data related to the reactor building and the risk of failure is dynamically quantified. A case study of an internal overpressure due to a hydrogen explosion is considered to exemplify the methodology.
\end{abstract}

KEYWORDS: Level 2 Probabilistic Risk Assessment, Dynamic reliability, Nuclear Power Plant, Reactor Building, Reinforced Concrete Containment, Aging, Degradation, Hydrogen Combustion. 


\section{List of acronyms}

$\begin{array}{ll}\text { ADAPT } & \text { Analysis of Dynamic Accident Progression Tree } \\ \text { BWR } & \text { Boiling Water Reactor } \\ \text { CDF } & \text { Core Damage Frequency } \\ \text { CoV } & \text { Coefficient of Variation } \\ \text { DDET } & \text { Discrete Dynamic Event Tree } \\ \text { DEF } & \text { Deflagration } \\ \text { DET } & \text { Detonation } \\ \text { EI } & \text { Early Ignition } \\ \text { ESP } & \text { Equipment Storage Pool } \\ \text { ET } & \text { Event Tree } \\ \text { FEM } & \text { Finite Element Model } \\ \text { LERF } & \text { Large Early Release Frequency } \\ \text { LRF } & \text { Large Release Frequency } \\ \text { LOCA } & \text { Loss of Coolant Accident } \\ \text { LODHR } & \text { Loss of Decay Heat Removal } \\ \text { LPSD } & \text { Low Power ShutDown } \\ \text { MC } & \text { Monte Carlo } \\ \text { MCDET } & \text { Monte Carlo Dynamic Event Tree } \\ \text { NPP } & \text { Nuclear Power Plant } \\ \text { NRC } & \text { Nuclear Regulatory Commission } \\ \text { OS } & \text { Order Statistics } \\ \text { PRA } & \text { Probabilistic Risk Assessment } \\ \text { RB } & \text { Reactor Building } \\ \text { RC } & \text { Reinforced Concrete } \\ \text { SFP } & \text { Spent Fuel Pool } \\ \text { TH } & \text { Thermal-Hydraulic } \\ \Delta \text { LERF } & \text { Increase in LERF } \\ & \end{array}$

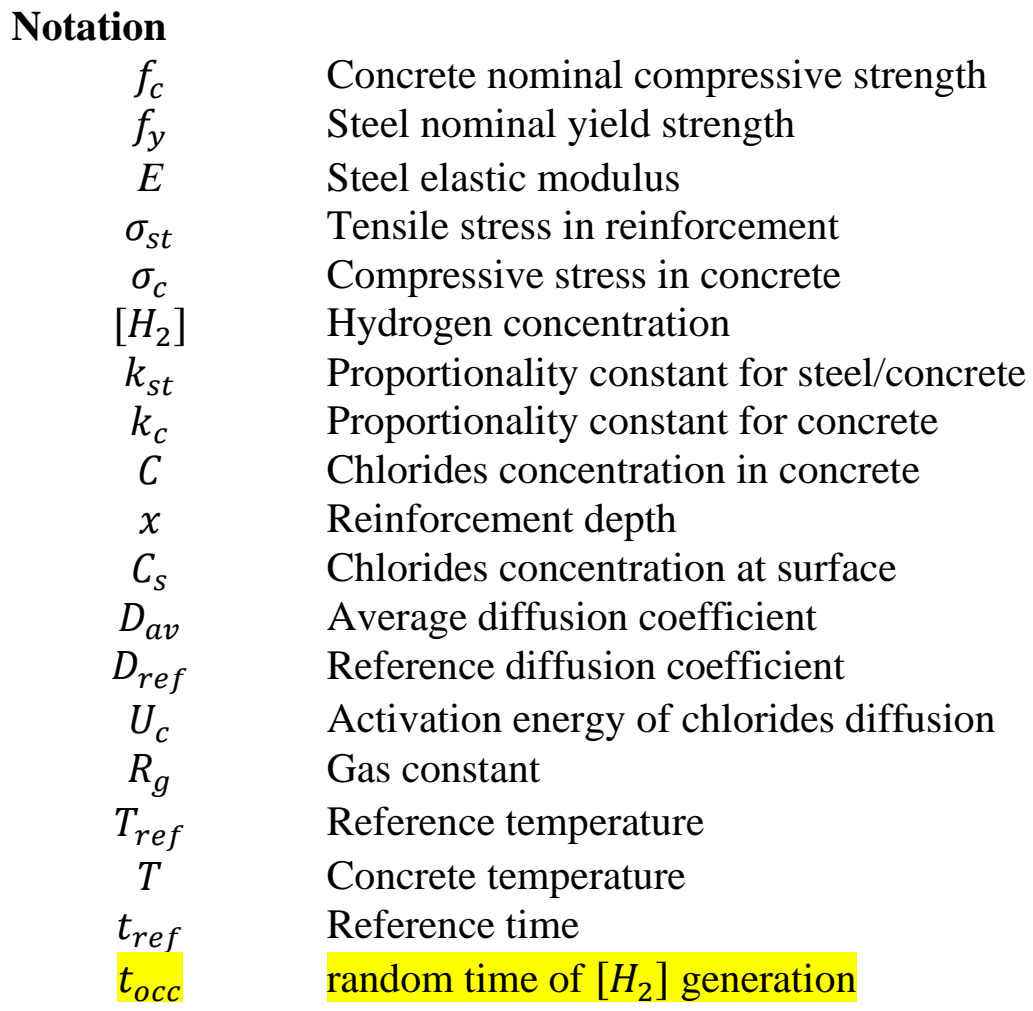




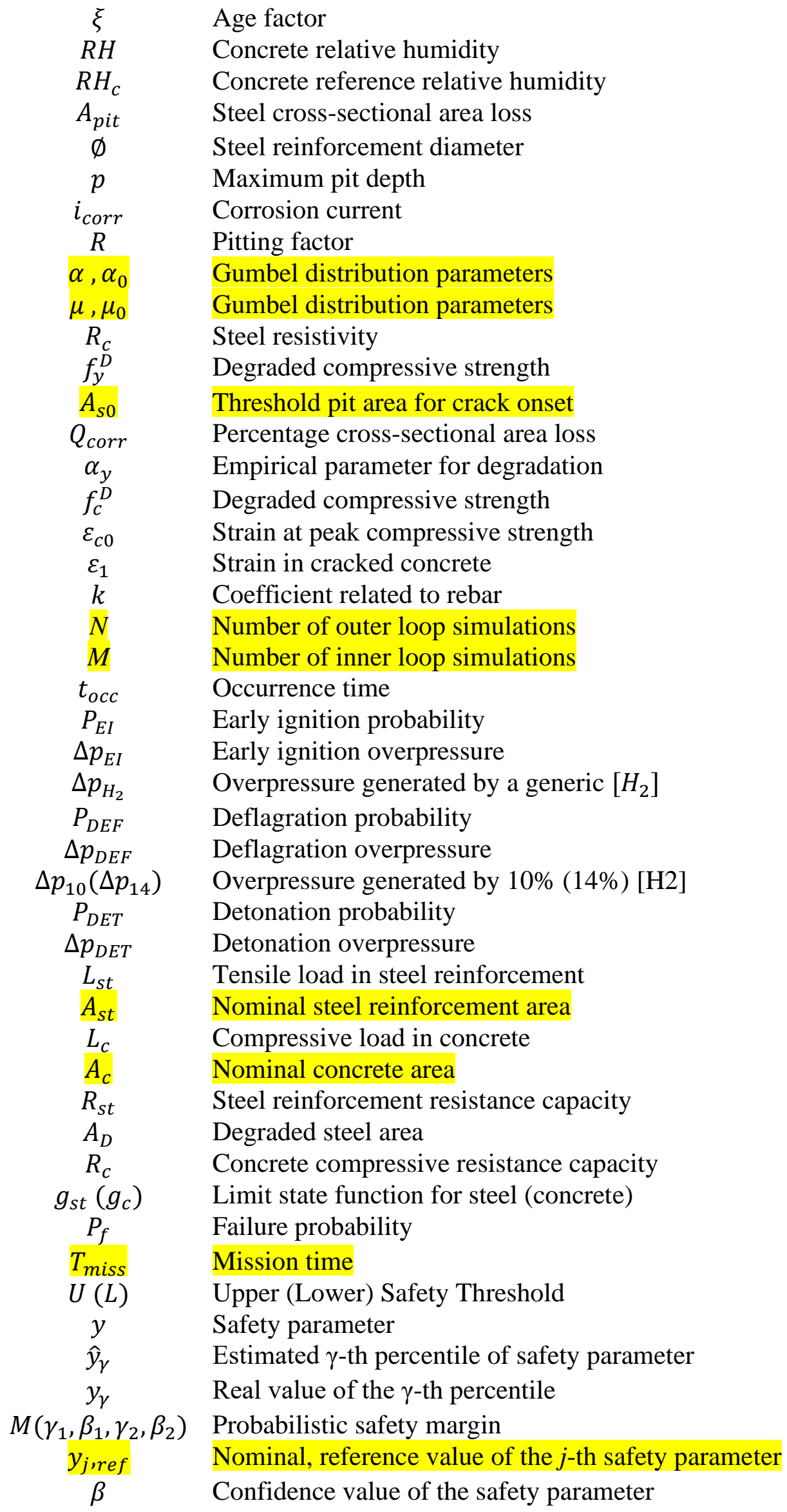




\section{Introduction}

Probabilistic Risk Assessment (PRA) is a comprehensive, structured and logical analysis method aiming at identifying and assessing risks in complex technological systems, such as Nuclear Power Plants (NPPs). A PRA is typically developed in three steps, Level 1, Level 2 and Level 3 (NUREG/CR-2300; NUREG/CR-2815): Level 1 assesses the Core Damage Frequency (CDF); Level 2, the Large Early Release Frequency (LERF) and the Large Release Frequency (LRF) of different types of isotopes due to Reactor Building (RB) failure; Level 3, the environmental and human health effects (IAEA, 1994).

Conventional PRA traditionally does not model explicitly time-dependent phenomena. In particular, in this work, we are concerned with the fact that, in Level 2 PRA, the effects of RB aging and degradation on its failure probability are not modeled. This can become critical also in view of the life extension of the existing (and aging) NPPs. To overcome this limitation, we embrace a dynamic reliability analysis framework to introduce a time-dependent physical model that describes RB aging and degradation and allows accounting for the effects on its resistance to the overloads developing during accident scenarios throughout its life (mission) time $T_{\text {miss }}$. Dynamic reliability analysis allows the integration of time-dependent phenomenological models with the models of the stochastic failure processes (Aldemir, 2013; Zio, 2014; Coyne \& Mosleh, 2018). Compared to traditional analysis, dynamic reliability analysis can provide a more realistic representation of the plant response to an accident, by the inclusion of a Best Estimate physical model.

Over the years, various approaches of dynamic reliability analysis have been developed, such as Cognitive Event Simulator, Monte Carlo Dynamic Event Tree (MCDET) (Kloos et al., 2006), Discrete Dynamic Event Tree (DDET) (Durga et al., 2011), Analysis of Dynamic Accident Progression Trees (ADAPT) (Aldemir, 2018). In literature, such approaches has so far regarded modelling of dynamic processes such as thermal-hydraulic (TH) transients, with focus also on radiological an structural aspects, initiated by the occurrence of accidents (Devooght, 1997; Labeau, 
Smidts, \& Swaminathan, 2000; Hakobyan et al., 2008; Secchi, Zio, \& Di Maio, 2008; Zio \& Di Maio, 2008 Di Maio, Baronchelli, Vagnoli, \& Zio, 2017).

In this work, we develop a dynamic reliability analysis for modeling the reduction of RB resistance due to Reinforced Concrete ( $\mathrm{RC}$ ) degradation by aging, thus targeting slow dynamics and long time horizons. Even though the general idea is not new (see Naus, Oland, \& Ellingwood, 1996), this is the first time, to the authors' knowledge, that an analytical and numerical procedure of this type is fully developed, addressing: (1) a sophisticated probabilistic load model for overpressure, (2) the complete 3D modelling of the RB structure, (3) a refined degradation model for RC and (4) a state-of-the-art reliability analysis procedure, which consistently accounts for both epistemic and aleatory uncertainties.

For illustration, we consider a Mark I Boiling Water Reactor (BWR) and build a dynamic reliability analysis model for estimating the RB failure probability following the combustion of hydrogen internally generated at a random time $t_{o c c}$. Low Power ShutDown (LPSD) is considered for the NPP, as it is of concern for the United States Nuclear Regulatory Commission (NRC) licensing (Wakefield, Budniz, \& Kiper, 2014).

The importance and possible consequences of the aging of the RB, which can lead to microstructural changes due to environmental factors, was recognized by many researchers; pioneering work, in this field, was performed by Naus and co-authors (Naus, 2007; Naus, Oland, \& Ellingwood, 1996). In fact, aging may impair the ability to withstand accidental internal overpressures, whose dominant mechanism, for NPPs RBs, is hydrogen combustion (Izquierdo et al., 2009; Fernández-Cosials et al., 2017; Mercurio, Andersen, \& Wagner, 2017). During accident sequences, the slow release of steam and non-condensable gas into the RB vault does not endanger the containment, because of controlled RB leakages, whereas pressure increase due to hydrogen combustion (either deflagrations or detonations) occurs more rapidly than leakage controlled pressure surge (Mercurio et al., 2017). 
In this work, to model the progression of the hydrogen combustion accident, and the related RB pressure surge and structural response, a probabilistic hydrogen combustion model (Camp et al., 1983; Mercurio et al., 2017) is coupled with a Finite Element Model (FEM) of the RB, whose parameters of structural properties are updated according to a probabilistic RC degradation model of literature, describing the pitting corrosion of steel reinforcement bars (rebars) induced by chlorides and leading to loss of cross-sectional area and concrete spalling, which in turns leads to RB resistance reduction (Stewart \& Rosowsky, 1998). The code MELCOR is used to evaluate the source term of each accidental sequence. The RB resistance, provided by the FEM and by the material degradation model, is compared to the overpressure generated by the probabilistic hydrogen combustion model, to get the time-dependent RB fragility curve. The uncertainties involved in the analysis (both epistemic and aleatory, such as degradation model and FEM parameters, and timing and magnitude of hydrogen combustion model parameters, respectively) are accounted for by calculating probabilistic safety margins (Helton, 2009, 2011; Di Maio, Picoco, Zio, \& Rychkov, 2017; Di Maio, Rai, \& Zio, 2016) that are calculated via a double loop Monte Carlo (MC) simulation approach of literature (Durga Rao, Kushwaha, Verma, \& Srividya, 2007). Eventually, time-dependent risk measures of LERF and $\triangle \mathrm{LERF}$ are calculated. The latter can, for example, serve the scope of optimally planning RB inspections, to keep LERF below the limits prescribed by the NRC in the Regulatory Guide 1.174 (Nuclear Regulatory Commission, 2018).

Figure 1 shows the overall scheme of the dynamic reliability analysis framework here developed for dynamically calculating the LERF and $\triangle \mathrm{LERF}$, with reference to a hydrogen combustion accident. 


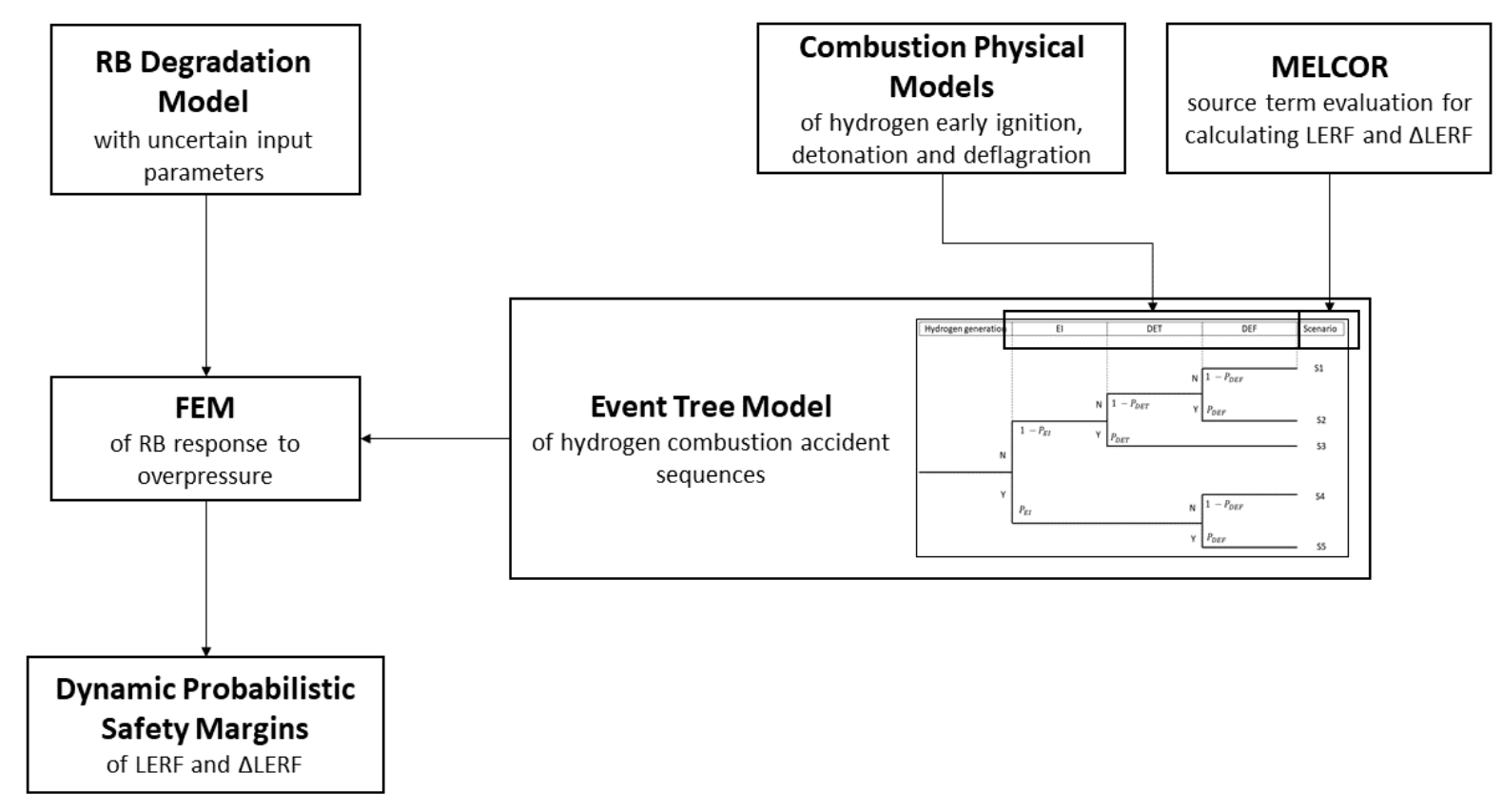

Figure 1 Dynamic reliability analysis framework

The remaining of the paper is structured as follows. Section 2 describes the FEM of the RB of the Mark I BWR. In Section 3 the RB degradation model is presented. Section 4 describes the hydrogen combustion model. Section 5 presents the integrated simulation approach for the combustion-FEMdegradation process. Section 6 describes the double-loop MC simulation approach for LERF and $\triangle$ LERF probabilistic safety margins quantification. Section 7 discusses the results. Finally, Section 8 draws some conclusions on the work. 


\section{The FEM of RB}

The RB of a Mark I BWR comprises several floors, beams, walls and other structural elements (Naus,

Oland, \& Ellingwood, 1996), as shown in Figure 2 where a simplified view of the vertical section looking West is given.

A Finite Element Model (FEM) of the upper part of the containment (highlighted by the dashed box in Figure 2) has been developed in Abaqus Software (Simulia, 2011), as shown in different views in Figure 3. It consists of the drywell, the spent fuel pool (SFP) and the equipment storage pool (ESP), with the dimensions reported in Figure 4. The FEM is developed for a limited portion of the RB because hydrogen generally accumulates at the top of the containment, making this part of the RB more likely to be subjected to hydrogen combustion (Kuznetsov, Yanez, Grune, Friedrich, \& Jordan, 2015).

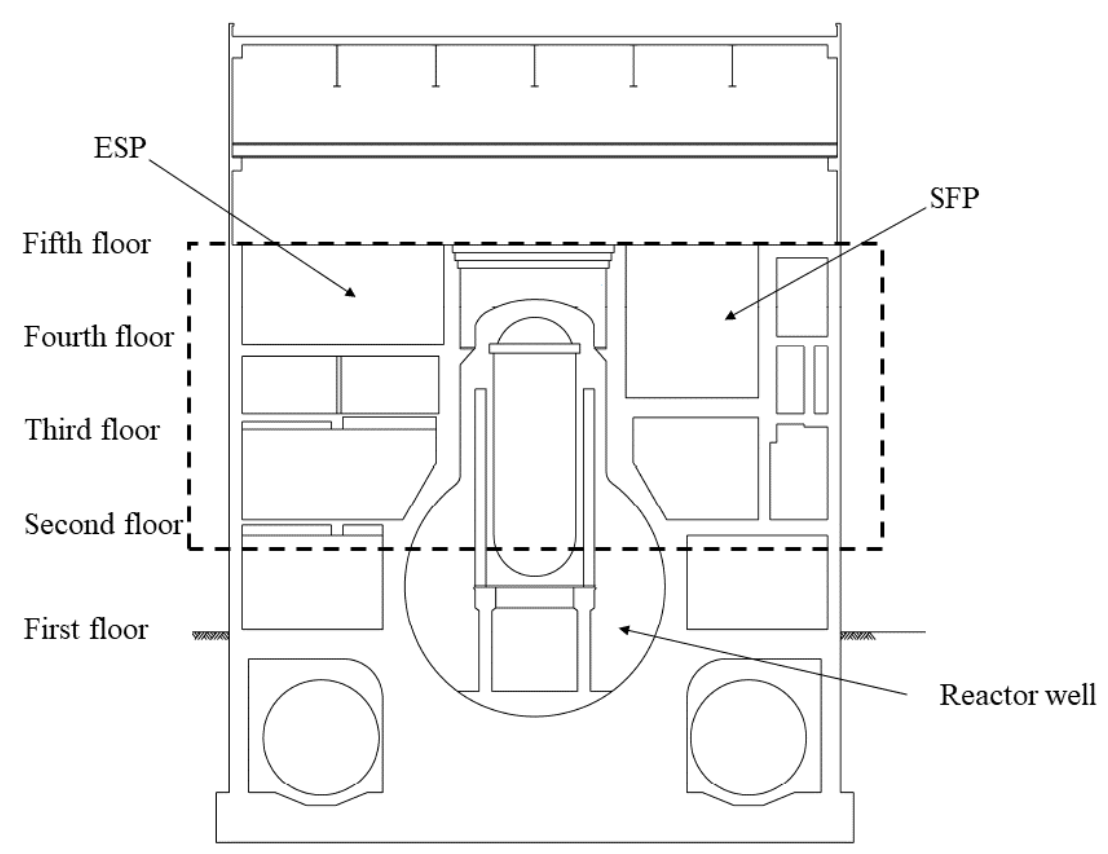

Figure 2 Vertical section looking West of the RB of a BWR Mark I 

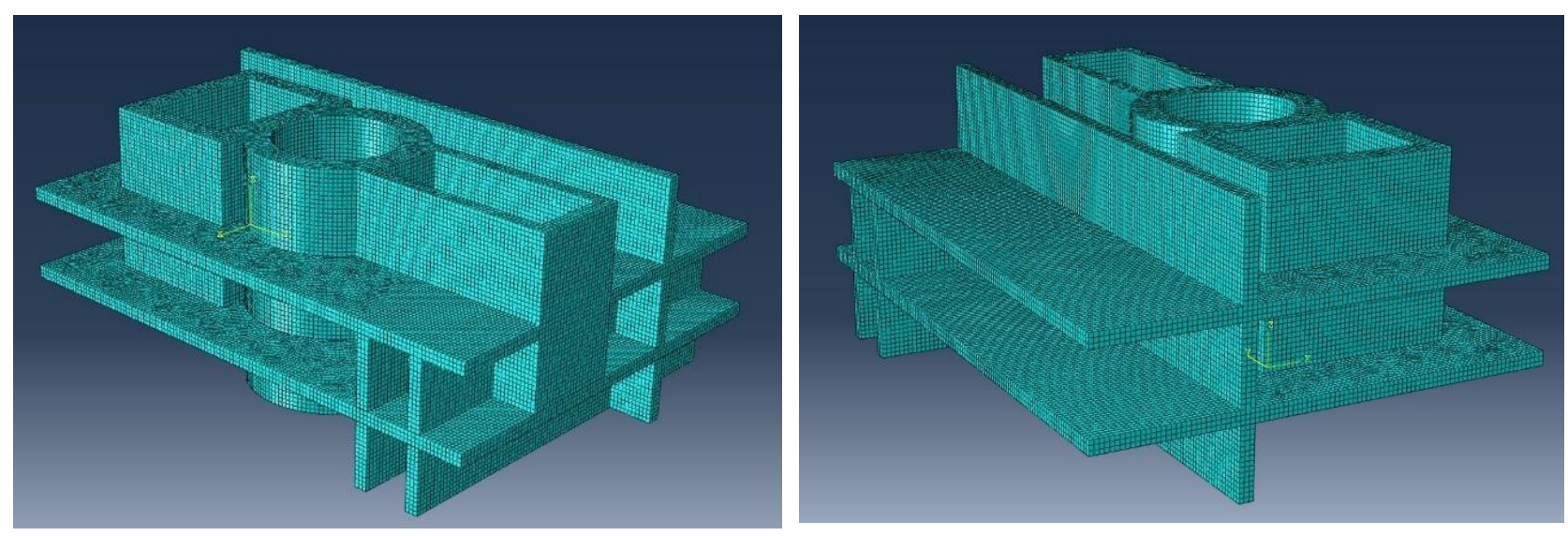

Figure 3 FEM of the main internal structural elements in the upper part of the RB (TEPCO, 2012)
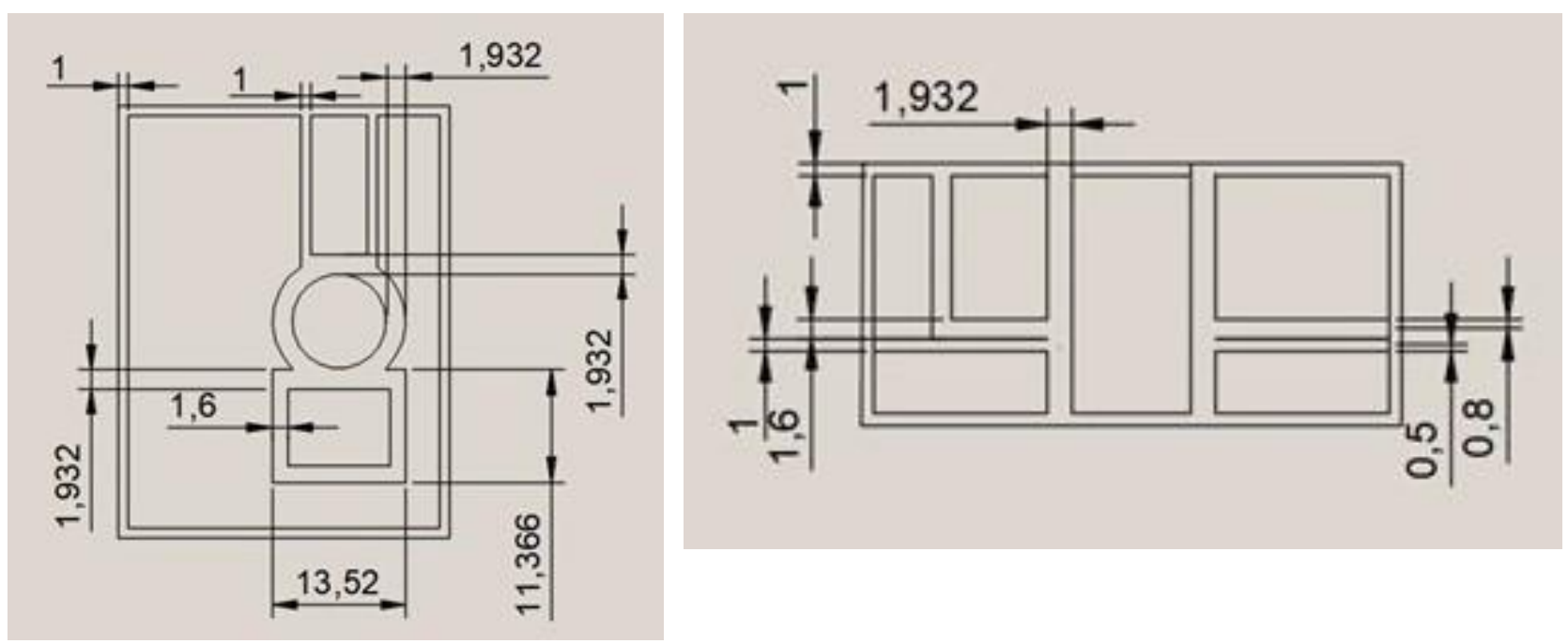

Figure 4 Dimensions of the main structural elements of the upper part of the $R B$

Hexahedral solid elements C3D8R have been adopted in the model, consisting of 8-node linear bricks, with reduced integration and hourglass control. Since the thickness of the internal horizontal plates is equal to $1.0 \mathrm{~m}$, the mesh has been generated with respect to an approximate global size of the finite elements of $0.33 \mathrm{~m}$ in order to correctly catch the shear and tensile/compressive response of the structural components. A uniform pressure equal to $1 \mathrm{kN} / \mathrm{m}^{2}$ has been separately applied to the walls of each main room of the upper part of the RB.

The RC consists of Type II Portland cement, with fine aggregates and various admixtures to enhance performances against environmental stressors. This results in a nominal compressive strength $f_{c}$ that 
follows a Gaussian distribution with mean $35 \mathrm{MPa}$ and coefficient of variation 0.12 (Naus, Oland, \& Ellingwood, 1996). The concrete reinforcement consists in $100 \mathrm{~cm}^{2} / \mathrm{m}$ of ASTM A - 615 Grade 60 \#18 steel, with nominal yield strength $f_{y}$ that follows a lognormal distribution with mean $420 \mathrm{MPa}$ and coefficient of variation 0.11, and elastic modulus $E$ equal to $200 \mathrm{GPa}$ (Naus, 2007; Naus, Oland, \& Ellingwood, 1996). In this work, it is assumed that tensile loads are withstood by steel reinforcements, compressive loads by concrete (Naus, 2007) and that stresses generated in the RC (i.e., $\sigma_{s t}$ the tensile stress in rebars and $\sigma_{c}$ the compressive stress in concrete) depend linearly on overpressure (that, in turn, depends on the hydrogen concentration $\left[H_{2}\right]$, see Section 4 ), as in Equations (1) and (2) below:

$$
\begin{gathered}
\sigma_{s t}(\Delta p)=k_{s t} \cdot \Delta p \\
\sigma_{c}(\Delta p)=k_{c} \cdot \Delta p
\end{gathered}
$$

where $\Delta p$ is the internal overpressure and $k_{s t}$ and $k_{c}$ are calculated by solving the FEM of the structure.

Figure 5 shows on the left the uniform pressure applied to the most critical room of the structure, in which span dimensions are larger and there are no internal walls, and on the right the contour plot of tensile/compressive loads on the associated horizontal plates.
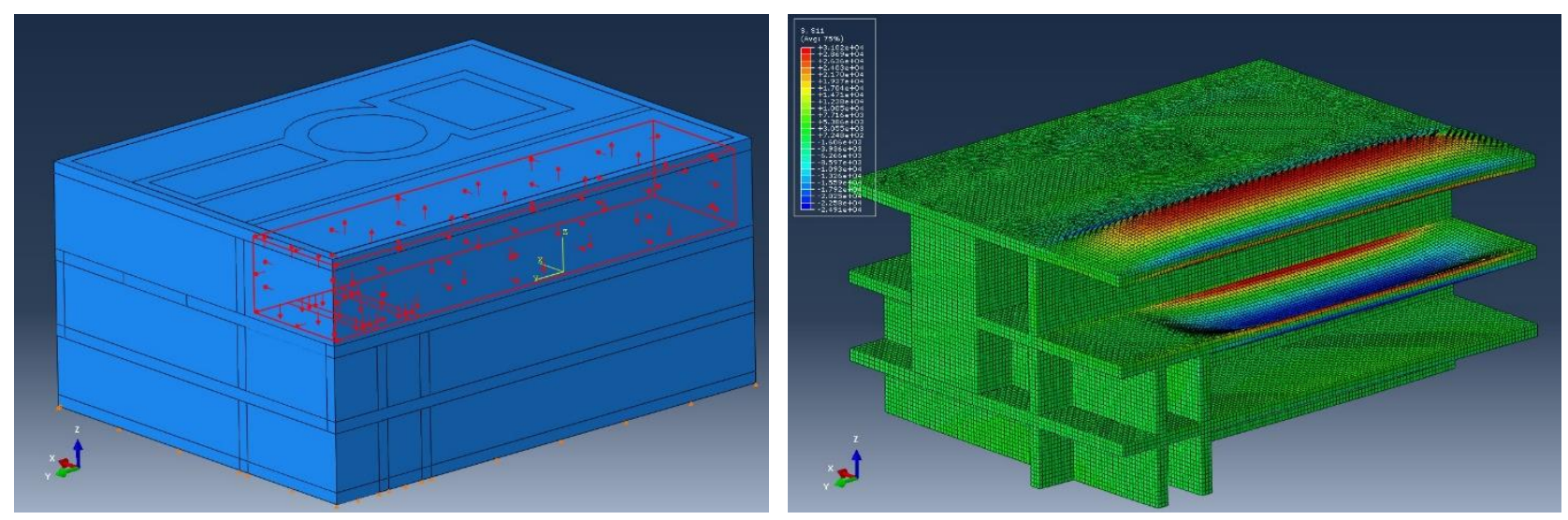

Figure 5 FEM applied loads and results for the studied case 


\section{RB degradation model}

Steel reinforcement nominal yield strength $f_{y}$ and concrete nominal compressive strength $f_{c}$ change with the increase of chlorides ion concentration in the concrete $C(x, t)$, up to reaching the threshold value $C_{t h}$ at the reinforcement depth $x$; at this level, the passive layer of the rebar is destroyed, and corrosion pits are generated and propagated through the rebar cross sectional area (Stewart, 2009; Stewart \& Rosowsky, 1998; Tuutti, 1982). The chloride-induced pitting corrosion process can, then, be divided into initiation and propagation phases: the former case concerns chlorides diffusion from the external surface to the rebar; the latter phase regard pits penetrating the steel (El Hassan, Bressolette, Chateauneuf, \& El Tawil, 2010; Tuutti, 1982; Vu \& Stewart, 2000).

Chlorides diffusion depends on many factors which are related to concrete properties (composition and microstructure) and exposure conditions (temperature, relative humidity, chlorides...), and can be modeled as in Equation (3) (El Hassan et al., 2010; Kwon, Na, Park, \& Jung, 2009; Luping \& Gulikers, 2007; Papakonstantinou \& Shinozuka, 2013b):

$$
C(x, t)=C_{s}\left[1-\operatorname{erf}\left(\frac{x}{2 \sqrt{D_{a v} t}}\right)\right]
$$

where $C(x, t)$ is the chlorides ion concentration at exposure time $t$ and reinforcement depth $x$ in the diffusion direction, $C_{s}$ is the chlorides concentration at surface and $D_{a v}$ is the average apparent diffusion coefficient that accounts for environmental conditions:

$$
D_{a v}(t)=\frac{1}{t} \int_{0}^{t} D_{r e f} \cdot \exp \left[\frac{U_{c}}{R_{g}}\left(\frac{1}{T_{r e f}}-\frac{1}{T}\right)\right]\left(\frac{t_{r e f}}{\tau}\right)^{\xi}\left[1+\frac{(1-R H)^{4}}{\left(1-R H_{c}\right)^{4}}\right]^{-1} d \tau
$$

In (4), $D_{\text {ref }}$ is the reference diffusion coefficient (see Table 1), $U_{c}$ the activation energy of the chlorides diffusion process $(\mathrm{kJ} / \mathrm{mol}), R_{g}$ the gas constant $\left(8.314 \frac{\mathrm{J}}{\mathrm{kg} \cdot \mathrm{mol}}\right), \quad T_{\text {ref }}$ the reference temperature of concrete $(296 \mathrm{~K}), T$ the current temperature of concrete $(\mathrm{K}), t_{\text {ref }}$ the reference time (28 days), $\xi$ a constant called age factor, $R H$ the relative humidity and $R H_{c}$ the reference humidity (0.75) (El Hassan et al., 2010). 
Table 1 summarizes the uncertainty distributions here assumed (in terms of mean and Coefficient of Variation (CoV)) (El Hassan et al., 2010; Papakonstantinou \& Shinozuka, 2013a; Mercurio et al., 2017).

\begin{tabular}{|c|c|c|c|c|c|}
\hline Parameter & Type & Symbol & Distribution & Mean & CoV \\
\hline $\begin{array}{l}\text { Threshold for chlorides } \\
\text { concentration }\end{array}$ & Epistemic & $C_{t h}$ & Uniform & $0.9 \mathrm{~kg} / \mathrm{m}^{3}$ & 0.19 \\
\hline Reinforcement depth & Epistemic & $x$ & Gaussian & $50 \mathrm{~mm}$ & 0.1 \\
\hline $\begin{array}{c}\text { Chlorides concentration at } \\
\text { surface }\end{array}$ & Epistemic & $C_{s}$ & Gaussian & $2.95 \mathrm{~kg} / \mathrm{m}^{3}$ & 0.5 \\
\hline Reference diffusion coefficient & Epistemic & $D_{\text {ref }}$ & Lognormal & $\begin{array}{c}6 \cdot 10^{-12} \\
\mathrm{~m}^{2} / \mathrm{s}\end{array}$ & 0.2 \\
\hline Temperature of concrete & Epistemic & $T$ & Gaussian & $296 \mathrm{~K}$ & 0.1 \\
\hline Age factor & Epistemic & $\xi$ & Beta & 0.15 & 0.3 \\
\hline Relative humidity & Epistemic & $R H$ & Gaussian & 0.75 & 0.1 \\
\hline Pitting factor & Epistemic & $R$ & Gumbel & 23.75 & 0.06 \\
\hline Yield Strength & Epistemic & $f_{y}$ & Gaussian & $420 \mathrm{MPa}$ & 0.11 \\
\hline Compressive Strength & Epistemic & $f_{c}$ & Gaussian & $35 \mathrm{Mpa}$ & 0.12 \\
\hline Hydrogen Concentration & Aleatory & {$\left[\mathrm{H}_{2}\right]$} & Uniform & 0 & 0.57 \\
\hline Early Ignition Probability & Aleatory & $P_{E I}$ & Gaussian & 0.5 & 0.1 \\
\hline Deflagration Probability & Aleatory & $P_{D E F}$ & Gaussian & 0.5 & 0.1 \\
\hline Detonation Probability & Aleatory & $P_{D E T}$ & Gaussian & \multicolumn{2}{|c|}{ See Eq. (13) } \\
\hline Early Ignition Overpressure & Aleatory & & Log Normal & \multicolumn{2}{|c|}{ See Eq. (11) } \\
\hline
\end{tabular}




\begin{tabular}{|c|c|c|c|c|c|}
\hline Deflagration Overpressure & Aleatory & & Log Normal & \multicolumn{2}{|c|}{ See Eq. (12) } \\
\hline Detonation Overpressure & Aleatory & & Uniform & $7 \mathrm{MPa}$ & 0.08 \\
\hline
\end{tabular}

Table 1 Uncertainty distributions of the degradation model parameters

The chlorides diffusion leads to pits generation and penetration into steel, whose loss of crosssectional area $A_{\text {pit }}(t)$ at time $t$ is defined as in Equation (5):

$$
A_{p i t}(t)= \begin{cases}A_{1}+A_{2} & \text { if } p(t) \leq \frac{\emptyset}{\sqrt{2}} \\ \frac{\pi \emptyset^{2}}{4}-A_{1}+A_{2} & \text { if } \frac{\emptyset}{\sqrt{2}} \leq p(t) \leq \emptyset \\ \frac{\pi \emptyset^{2}}{4} & \text { if } p(t) \geq \emptyset\end{cases}
$$

where $A_{1}=0.5\left[\theta_{1}\left(\frac{\emptyset}{2}\right)^{2}-b\left|\frac{\emptyset}{2}-\frac{p(t)^{2}}{\emptyset}\right|\right], A_{2}=0.5\left[\theta_{2} p(t)^{2}-b \frac{p(t)^{\wedge} 2}{\emptyset}\right]$

$b(t)=2 p(t) \sqrt{1-\left(\frac{p(t)}{\emptyset}\right)^{2}}, \theta_{1}=2 \arcsin \left(\frac{b}{\varnothing}\right), \theta_{2}=2 \arcsin \left(\frac{b}{2 p(t)}\right), \emptyset$ is the rebar diameter and $p(t)$ is the maximum pit depth that is reached in the rebar at time $t$, defined as in Equation (6) (Stewart, 2009):

$$
p(t)=0.0116 R \int i_{c o r r}(t) d t
$$

where $i_{\text {corr }}$ is the corrosion current density, $R$ the pitting factor (known to be distributed as a Gumbel (EV - Type I) with modified parameters $\mu=\mu_{0}+\frac{1}{\alpha_{0}} \ln \left(\frac{L_{U}}{L_{0}}\right)$ and $\alpha=\alpha_{0}$ (Stewart, 2009), where $\alpha_{0}, \mu_{0}$ are the Gumbel parameters derived from pitting data for a reinforcement of length $L_{0}$ and $L_{U}$ is the length of a generic reinforcement).

For completeness, $i_{c o r r}$ can be modeled as in Equations (7) (Liu \& Weyers, 1998):

$\ln \left(1.08 i_{\text {corr }}(t)\right)=7.89+0.7771 \ln (1.69 \cdot C(x, t))-\frac{3006}{T}-0.000116 R_{c}+2.24 t^{-0.215}+$

$+N(0,0.3312)$ 
where $R_{c}$ is the rebar resistance that can be calculated as in Equation (8):

$$
\ln \left(R_{c}\right)=8.03-0.549 \ln (1+1.69 C(x, t))+N(0,0.1203)
$$

Finally, the loss of cross-sectional area $A_{\text {pit }}(t)$ reduces steel reinforcement performance by reducing the nominal yield strength $f_{y}$, resulting in the degraded yield strength $f_{y}^{D}(t)$ at time $t$ according to Equation (9) (Du, Clark, \& Chan, 2005):

$$
f_{y}^{D}(t)=\left(1-\alpha_{y} Q_{c o r r}(t)\right) f_{y}
$$

where $\alpha_{y}$ is an empirical parameter (here taken equal to 0.005, as in (Du et al., 2005)), and $Q_{c o r r}(t)=\frac{A_{p i t}(t)}{A} \cdot 100$ is the percentage of cross section loss due to corrosion.

Furthermore, as long as the pit area increases, $f_{y}^{D}(t)$ decreases and corrosion products, that have a larger specific volume than rebar material, accumulate on the external surface of the rebar; this causes tensile stresses in the surrounding concrete, leading to cracking when the pit area reaches the threshold value $A_{s 0}$ and, in turn, to the reduction of the nominal concrete compressive strength $f_{c}$ into $f_{c}^{D}(t)$ at time $t$, according to Equation (10) (Coronelli \& Gambarova, 2004):

$$
f_{c}^{D}(t)=\frac{f_{c}}{1+k \cdot \frac{\varepsilon_{1}(t)}{\varepsilon_{c 0}}}
$$

where $\varepsilon_{c 0}$ is the strain at peak compressive strength $f_{c}, \varepsilon_{1}(t)$ is the tensile strain in cracked concrete, $k$ is a coefficient related to the bar roughness and diameter (here taken equal to 0.01 as in (Coronelli \& Gambarova, 2004)).

It must be pointed out that the degradation model here presented, and hereafter adopted for the reliability analysis, neglects the spatial distribution of damage: this can be considered of sufficient level of detail to show the complexity of the phenomena modelled and the need for a dynamic reliability analysis. 


\section{Hydrogen generation and combustion model}

We consider the $\mathrm{RB}$ resistance to be verified to withstand the overpressure generated in a hydrogen combustion accident. During BWR operation, hydrogen is produced by steam-zirconium and steamsteel reactions (Camp et al., 1983) in a controlled way to keep it below the combustion concentration threshold, although mixing with surrounding air in a non-uniform manner (i.e. hydrogen migrates towards higher floors of the RB). During an accident, the concentration might exceed the combustion threshold especially in the highest RB floors, where SFP and ESP are located (as described in Section 2). In this paper, hydrogen generation is assumed to occur during an LPSD state due to an SFP failure (i.e., for a Loss Of Decay Heat Removal (LODHR) or SFP Loss Of Coolant Accident (LOCA) that can cause spent fuel overheating and the consequent abnormal hydrogen production). Under these circumstances and a predefined SFP radioactive inventory, magnitude and timing of the release can be calculated using the MELCOR code for simulating accident progression and the behavior of the fission products (Mercurio et al., 2017; Sandia National Laboratories, 2017). Indeed, MELCOR is a fully integrated, engineering-level computer code that models the progression of severe accidents in light water reactor nuclear power plants. It can simulate many physical processes following a severe accident: thermal-hydraulic response in the reactor coolant system, reactor cavity, containment, and confinement buildings; core heatup, degradation and relocation; core-concrete attack; hydrogen production, transport, and combustion; fission product release and transport; and the impact of engineered safety features on thermal-hydraulic and radionuclide behavior. Thus, the time-dependent evolution of the hydrogen production during the SFP failure considered in the case of application could be simulated by MELCOR. However, in this work, neither the time-dependent evolution of hydrogen production nor the duration of the particular severe accident considered are modelled by

MELCOR, but rather a random amount of hydrogen concentration $\left[\mathrm{H}_{2}\right]$ is assumed to be generated in the uniform range $[0,100] \%$ at a random time $t_{\text {occ }}$, also uniformly distributed in $[0,100]$ years. The NPP mission time $T_{\text {miss }}$, has been considered 100 years, in light of the considerations pointed out in 
(Nuclear Regulatory Commission, 2017) where the NRC license renewal program for existing plants is considered and claimed to be possibly extended to 100 years.

As known, hydrogen concentration $\left[\mathrm{H}_{2}\right]$ is the parameter controlling the probabilities of the different hydrogen combustion modes, as summarized in Table 2 (Camp et al., 1983).

\begin{tabular}{|l|l|}
\hline Hydrogen concentration [\%] & Combustion mode \\
\hline $0-4$ & Non-combustible \\
\hline $4-10$ & Early Ignition (EI) \\
\hline $10-14$ & Deflagration (DEF) \\
\hline $14-59$ & Detonation (DET) \\
\hline $59-75$ & Deflagration (DEF) \\
\hline $75-100$ & Non-combustible \\
\hline
\end{tabular}

Table 2 Hydrogen concentration and related combustion mode

Early Ignition (EI) consists in hydrogen combustion close to the flammability limit, that can lead to deflagration (DEF) but can never progress to detonation (DET). When EI is not triggered, both DET and DEF must be considered as possible scenarios following hydrogen concentration build up. The Event Tree (ET) of Figure 6 shows the five different scenarios (S1 to S5) of progression of hydrogen generation into one of the combustion modes of Table 2. 


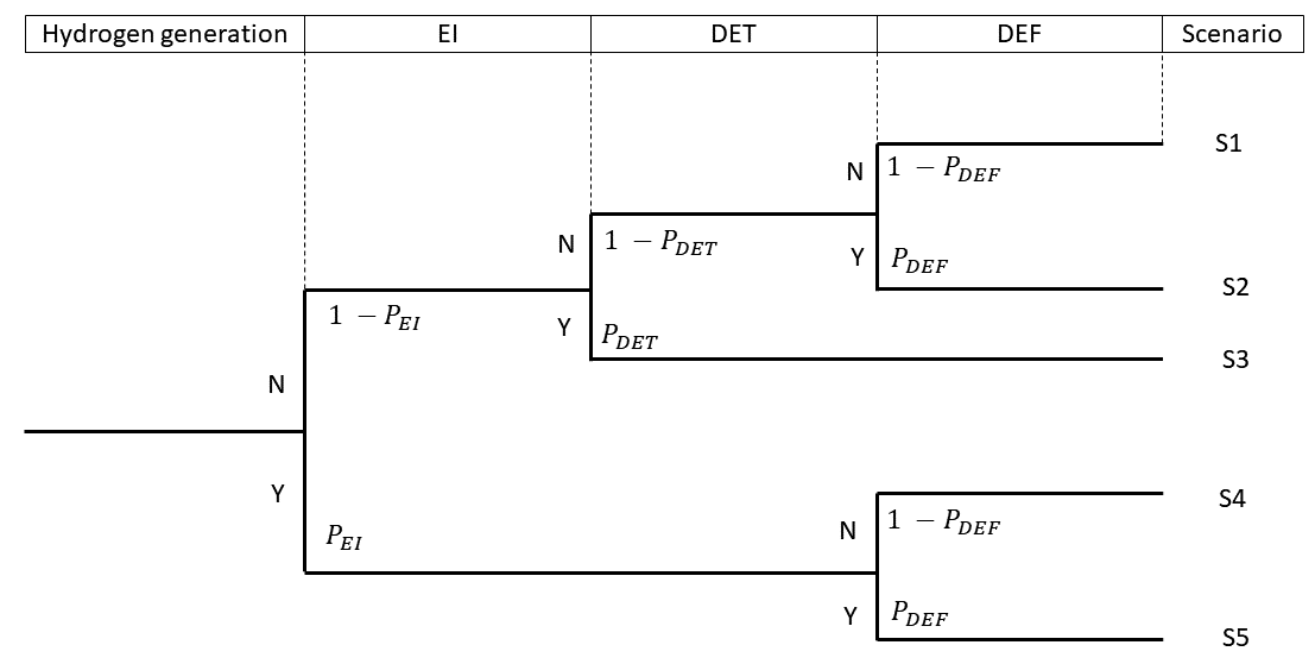

Figure 6 Hydrogen combustion Event Tree

The probabilities of occurrence of the five scenarios in Figure 6 depend on the probabilities of EI, DEF and DET, $P_{E I}, P_{D E F}, P_{D E T}$, respectively, whose values are taken from (Mercurio et al., 2017).

The probability $P_{E I}$ that EI occurs is assumed to be normally distributed with mean 0.5 and standard deviation 0.05 , whereas the resulting $\mathrm{RB}$ overpressure probability distribution $\operatorname{Pr}(\Delta P=\Delta p \mid E I)$ is assumed to be lognormal with mean $\ln \left(\Delta p_{E I}\right)$ and standard deviation $\sigma_{E I}$, as in (Mercurio et al., 2017) (see Equation (11)):

$$
\operatorname{Pr}(\Delta P=\Delta p \mid E I) \sim L N\left(\ln \left(\Delta p_{E I}\right), \sigma_{E I}\right)
$$

where $\Delta p_{E I}=\left\{\begin{array}{l}\Delta p_{H_{2}} \text { if }\left[H_{2}\right]<10 \% \\ \Delta p_{10} \text { if }\left[H_{2}\right]>10 \%\end{array}, \sigma_{E I}=\sqrt{\frac{\Delta p^{*}-\Delta p}{2}}, \Delta p^{*}=\left\{\begin{array}{l}\Delta p_{H_{2}} \text { if }\left[H_{2}\right]>10 \% \\ \Delta p_{10} \text { if }\left[H_{2}\right]<10 \%\end{array}\right.\right.$

where $\Delta p_{\mathrm{H}_{2}}$ is the pressure generated while a mixture with $\left[\mathrm{H}_{2}\right]$ hydrogen concentration is burning, whereas $\Delta p_{10}$ the maximum pressure generated while a mixture with $10 \%$ hydrogen is burning.

When EI is not triggered, the hydrogen concentration keeps increasing and can potentially lead to concentrations that may originate DEF, whose probability of occurrence $P_{D E F}$ is assumed to be normally distributed with mean 0.5 and standard deviation 0.05 . The related overpressure probability distribution $\operatorname{Pr}(\Delta P=\Delta p \mid D E F)$ is assumed lognormal with mean $\ln \left(\Delta p_{D E F}\right)$ and standard deviation $\sigma_{D E F}$, as outlined in Equation (12): 


$$
\operatorname{Pr}(\Delta P=\Delta p \mid D E F) \sim L N\left(\ln \left(\Delta p_{D E F}\right), \sigma_{D E F}\right)
$$

where $\Delta p_{D E F}=\left\{\begin{array}{lc}\Delta p_{H_{2}} & \text { if }\left[H_{2}\right]<14 \% \\ \Delta p_{14} & \text { if }\left[H_{2}\right]>14 \%\end{array}, \sigma_{D E F}=\sqrt{\frac{\Delta p^{*}-\Delta p}{2}}, \Delta p^{*}=\left\{\begin{array}{ll}\Delta p_{H_{2}} & \text { if }\left[H_{2}\right]>14 \% \\ \Delta p_{14} & \text { if }\left[H_{2}\right]<14 \%\end{array}\right.\right.$,

where $\Delta p_{14}$ is the maximum pressure generated while a mixture with $14 \%$ hydrogen is burning.

DET leads to the highest overpressure inside the containment. Its probability of occurrence is assumed to be normal with mean $P_{D E T}$ and standard deviation 0.02 (see Equation (13)):

$$
P_{D E T}= \begin{cases}0.01 & \text { if }\left[H_{2}\right]<14 \% \text { or }\left[H_{2}\right] \geq 59 \% \\ 1 & \text { if }\left[H_{2}\right] \geq 28 \% \text { or }\left[H_{2}\right]<45 \% \\ 10^{\left(\frac{1}{7}\left[H_{2}\right]-4\right)} & \text { if }\left[H_{2}\right] \geq 14 \% \text { or }\left[H_{2}\right]<28 \% \\ 10^{\left(-\frac{1}{7}\left[H_{2}\right]-\frac{45}{7}\right)} & \text { if }\left[H_{2}\right] \geq 45 \% \text { or }\left[H_{2}\right]<59 \%\end{cases}
$$

The related overpressure $\Delta p_{D E T}$ is assumed to be generated by a uniform distribution $\operatorname{Pr}(\Delta P=\Delta p \mid D E T) \sim U(6,8)$ bar.

MELCOR calculations were performed in (Mercurio et a., 2018) for each scenario of the ET of Figure 6 to evaluate the source term, i.e., the amount and type of radioactive material released. For each scenario, both LERF or LRF can be calculated (Rebollo et al., 2016). In this work, in line with (Mercurio et al., 2017; Mercurio et al., 2018), the release of ${ }^{137} \mathrm{Cs}$ discriminates between LERF and LRF.

A summary of the characterization of the scenarios of the ET of Figure 6 is given in Table 3.

\begin{tabular}{|l|l|l|l|}
\hline Scenario & RB end state & Consequence & Note \\
\hline S1 & Safe & LRF & RB leakage \\
\hline S2 & Failed & LRF & Slow release \\
\hline S3 & Failed & LERF & Early release \\
\hline S4 & Safe & LRF & RB leakage \\
\hline S5 & Failed & LERF & Early release \\
\hline
\end{tabular}

Table 3 Characteristics of the scenarios of the ET in Figure 6 (Mercurio et al., 2017) 


\section{Dynamic reliability analysis framework}

In this Section, we present the first MC loop of the dynamic reliability analysis of an SFP failureinitiated hydrogen combustion accident scenario during LPSD considering the aging of RB, as described in Section 2. This loop will be embedded in the two-loops MC approach that will be described in Section 6. As previously said, a physical model of rebar pitting corrosion is used to update the resistance capacity of the RB to withstand the overpressure generated by the hydrogen combustion that may occur in the RB, and, ultimately, the frequency of RB early failure and the consequent LERF and $\triangle \mathrm{LERF}$.

The procedure, schematized in the flowchart of Figure 8, is summarized as follows.

1) Set $M=1$;

2) Set $t=0$;

3) For each $m$-th simulation, simulate hydrogen combustion occurrence by sampling the occurrence time $t_{o c c}$ and the hydrogen concentration $\left[\mathrm{H}_{2}\right]$ that has triggered the combustion. Simulate accident progression as in the ET of Figure 6, using Equations (11) to (13), randomly selecting the combustion mode and the generated overpressure. Calculate the load that the RB is subjected to, as in Equations (14) and (15):

$$
\begin{gathered}
L_{s t}\left(\left[H_{2}\right]\right)=\sigma_{s t}\left(\left[H_{2}\right]\right) A_{s t} \\
L_{c}\left(\left[H_{2}\right]\right)=\sigma_{c}\left(\left[H_{2}\right]\right) A_{c}
\end{gathered}
$$

4) While $t<t_{o c c}$, simulate the chlorides ions diffusion with Equation (3) with a sampled set of environmental conditions (see Table 1) and calculate $C(x, t=t+1)$. When $C(x, t)=C_{t h}$, simulate pits penetration into steel (i.e., the cross sectional area loss $A_{\text {pit }}(t)$ ) by means of Equation (5) and calculate rebar degraded yield strength $f_{y}^{D}(t)$ by Equation (9), and the reinforcement resistance $R_{s t}(t)$ by Equation (16): 


$$
R_{s t}(t)=f_{y}^{D}(t) A_{D}(t)
$$

When $A_{p i t}(t)>A_{s 0}$ calculate concrete degraded compressive strength $f_{c}^{D}(t)$ by Equation (10) and concrete resistance with Equation (17):

$$
R_{c}(t)=f_{c}^{D}(t) A_{c}
$$

5) When $t=t_{o c c}$, determine whether the structure fails or not, evaluating the limit state function $g\left(t,\left[H_{2}\right]\right)$ as the difference between the capacity $R(t)$ and the load $L\left(\left[H_{2}\right]\right)$ (Melchers \& Beck, 2018; Thoft-Christensen \& Beck, 1982):

$$
g\left(t,\left[H_{2}\right]\right)=R(t)-L\left(\left[H_{2}\right]\right)
$$

where $g\left(t,\left[H_{2}\right]\right)=\min \left\{g_{s t}\left(t,\left[H_{2}\right]\right), g_{c}\left(t,\left[H_{2}\right]\right\}\right.$ and

$$
\begin{gathered}
g_{s t}\left(t,\left[H_{2}\right]\right)=R_{s t}(t)-L_{s t}\left(\left[H_{2}\right]\right)=f_{y}^{D}(t) A_{D}(t)-\sigma_{s t}\left(\left[H_{2}\right]\right) A_{s t} \\
g_{c}\left(t,\left[H_{2}\right]\right)=R_{c}(t)-L_{c}\left(\left[H_{2}\right]\right)=f_{c}^{D}(t) A_{D}(t)-\sigma_{c}\left(\left[H_{2}\right]\right) A_{c}
\end{gathered}
$$

6) When $t=T_{\text {miss }}$, end simulation.

7) $M=M+1$;

8) Repeat from 2) to 7)

When $M=1000$ :

9) Calculate the probability of failure $P_{f}(t)$ at each time $t$ by Equation (21):

$$
P_{f}(t)=\operatorname{Pr}\left\{g_{s t}\left(t,\left[H_{2}\right]\right)<0\right\} \cup \operatorname{Pr}\left\{g_{c}\left(t,\left[H_{2}\right]\right)<0\right\}
$$

Figure 7 illustrates this concept: at each time $t$, the area $P_{f}(t)$ represents the condition in which the overpressure load $L\left(\left[H_{2}\right]\right.$ is incidentally larger than the capacity $R(t)$, i.e., the structure is failed. 


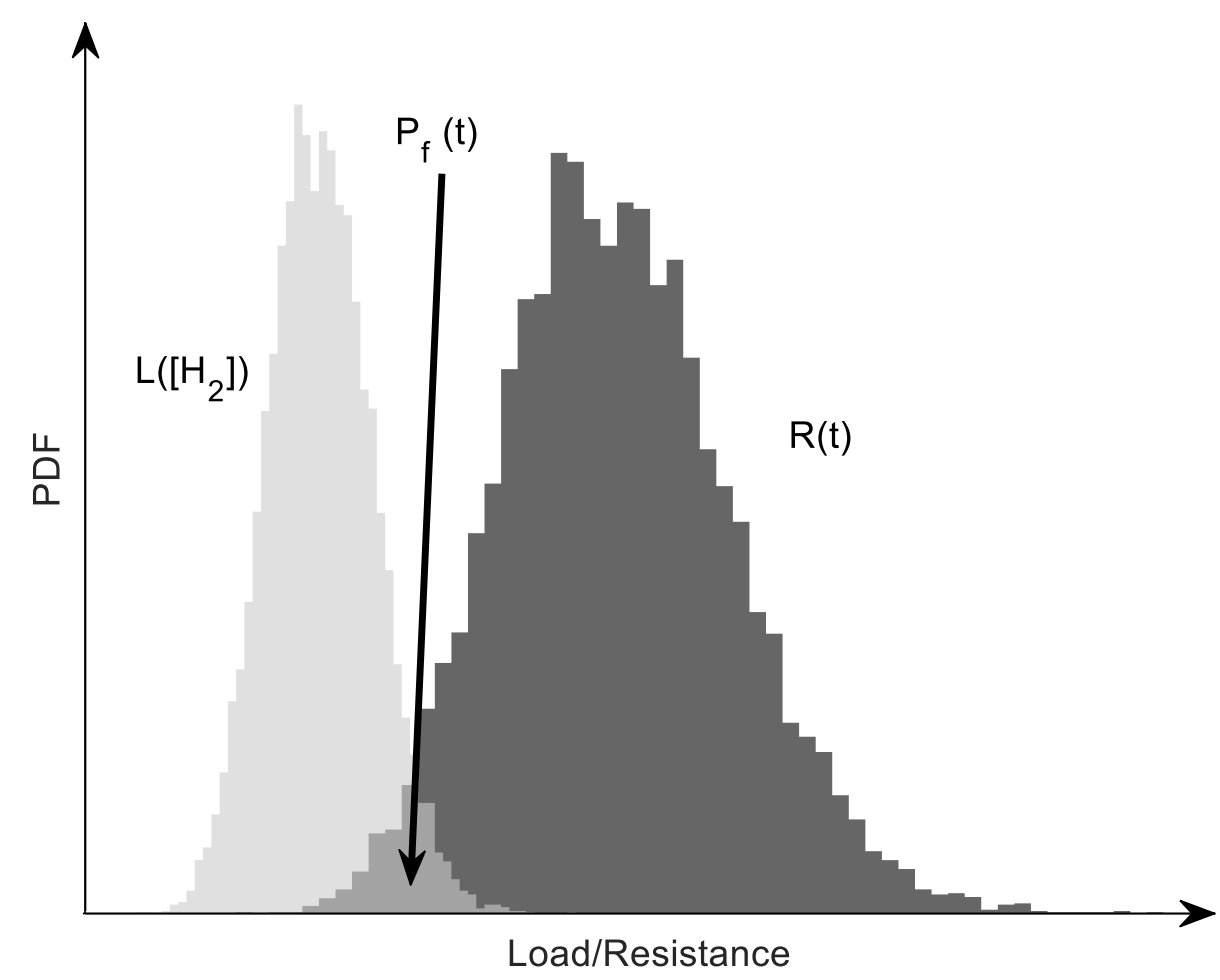

Figure 7 Capacity vs load curve to estimate failure probability. The dashed area represents the failure probability.

10) Calculate LERF(t) considering failure probabilities originated by S3 and S5 scenarios only (being the two scenarios implying a LERF, as assumed in (Mercurio et al., 2017) and reported in Table 3).

11) Calculate the increase in LERF (i.e., $\triangle \mathrm{LERF}$ ) at time $t$ as Equation (22):

$$
\Delta \operatorname{LERF}(t)=\operatorname{LERF}(t)-\operatorname{LERF}(t-1)
$$

where $\operatorname{LERF}(\mathrm{t})$ is the LERF that is calculated at the actual time (with the RB in the current degradation state) and LERF(t-1) is the LERF that was calculated at the previous time step (where the RB was less degraded than at the current time $t$ ). 


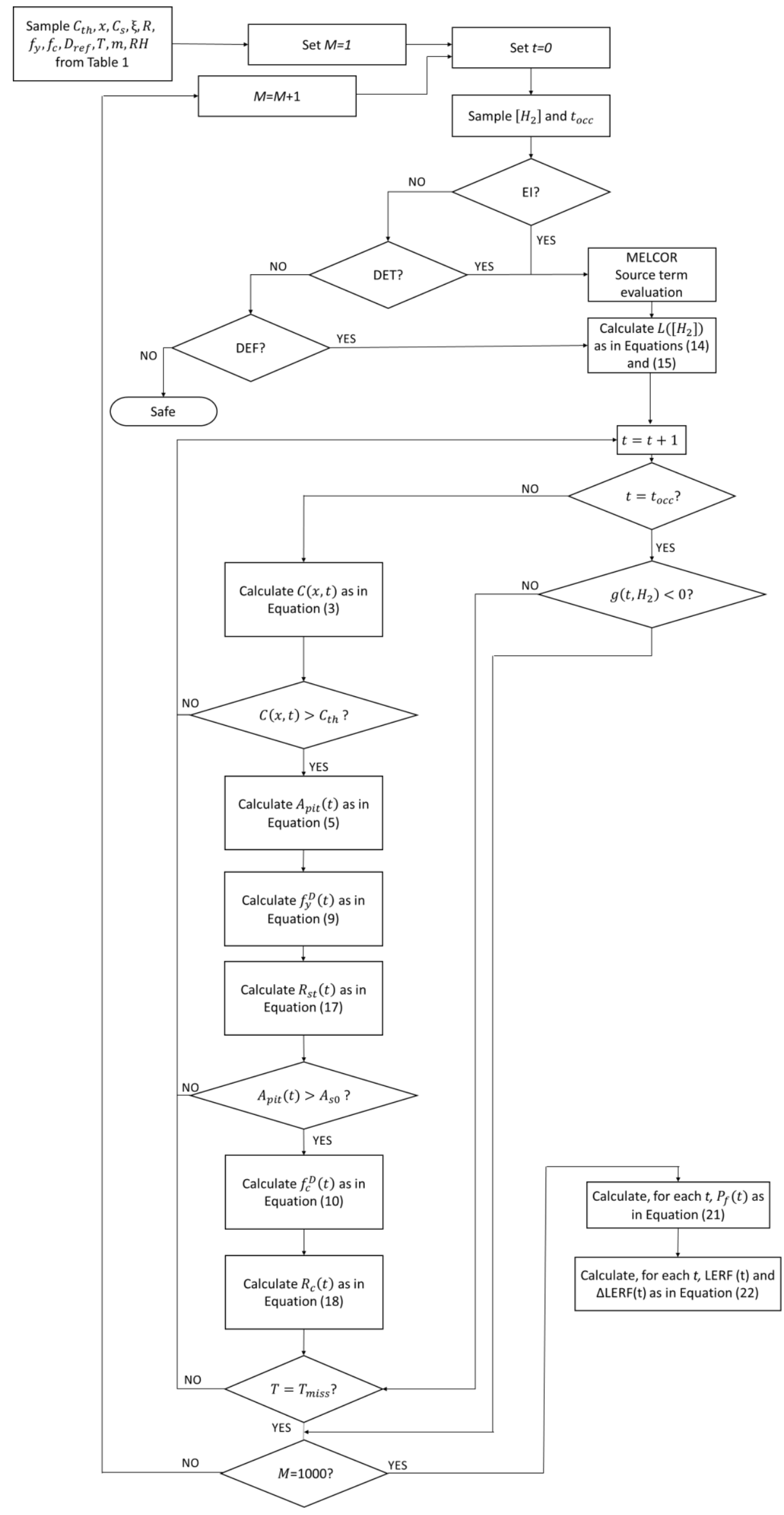

Figure 8 Flowchart of the first-loop simulation procedure 


\section{Probabilistic Safety Margins quantification}

Here, safety margin is taken as the difference between the (conservatively) computed value reached by a selected safety parameter $y_{j}$ and an upper (lower) safety threshold $U_{j}\left(L_{j}\right)$ for a specific accident scenario (Helton, 2009, 2011; Di Maio et al., 2016). To explicitly account for uncertainty and to reduce conservatism, the safety margin can be defined in probabilistic terms as the difference between the upper (lower) threshold $U_{j}\left(L_{j}\right)$ and the estimate $\hat{y}_{\gamma_{j}}$ of a specific $\gamma$ percentile $y_{\gamma j}$ of the distribution of the safety parameter $y_{j}$ (Di Maio, Picoco, et al., 2017; Di Maio et al., 2016; Martorell et al., 2006, 2009), as in Equation (23):

$$
M\left(\gamma_{1}, \beta_{1}, \gamma_{2}, \beta_{2}\right)=\left\{\begin{array}{cl}
\frac{U_{j}-\hat{y}_{\gamma j}}{U_{j}-y_{j, r e f}} & \text { if } \hat{y}_{\gamma j} \leq U_{j} \\
0 & \text { if } U_{j} \leq \hat{y}_{j} \\
1 & \text { if } \hat{y}_{\gamma j} \leq y_{j, r e f}
\end{array}\right.
$$

where $\beta_{1}=\operatorname{Pr}\left(y_{\gamma 1}<\hat{y}_{\gamma 1}\right)$ is defined as the confidence on the estimate of the actual percentile $y_{\gamma 1}$, in the same way, $\beta_{2}=\operatorname{Pr}\left(y_{\gamma_{2}}<\hat{y}_{\gamma 2}\right)$, and $y_{j, r e f}$ is the nominal, reference value of the safety parameter $j$.

In this work, we take as safety parameters $y_{1}=L E R F$ and $y_{2}=\Delta L E R F, y_{1, r e f}$ is the LERF value for the case of no corrosion, $y_{2, r e f}$ is the $\triangle L E R F$ for the case of no corrosion, and $\hat{y}_{\gamma 1}$ and $\hat{y}_{\gamma^{2}}$ are estimated using Order Statistics (OS) (Nutt \& Wallis, 2004), that allows obtaining, with the desired confidence $\beta$, the estimate of the $\gamma$ percentile of the distribution of the safety parameter, limiting the computational cost related to the number $N$ of code simulations (Di Maio et al., 2016; Nutt \& Wallis, 2004). In particular, the Coverage approach (Wald, 1943) seems to suit well to our case, since it provides, with a given confidence, the estimates of tolerance limits (i.e., percentiles) of the distribution of the $N$ sorted values of correlated outputs (LERF and $\triangle \mathrm{LERF}$, in our case) accounting for the joint probability distribution of the outputs (Nutt \& Wallis, 2004).

Following the approach proposed in (Helton, 1998) and, then, applied in (Kloos et al., 2002; Durga

Rao et al., 2007), a two-loop MC simulation is implemented, where an external loop with $N=59$ allows 
sampling values for inputs affected by epistemic uncertainties (e.g., degradation model and FEM) and an inner loop with $M=1000$ allows sampling (for each set of sampled values in the outer loop) values of input parameters affected by aleatory uncertainty (e.g., hydrogen combustion accident timing and magnitude), as shown in Figure 9.

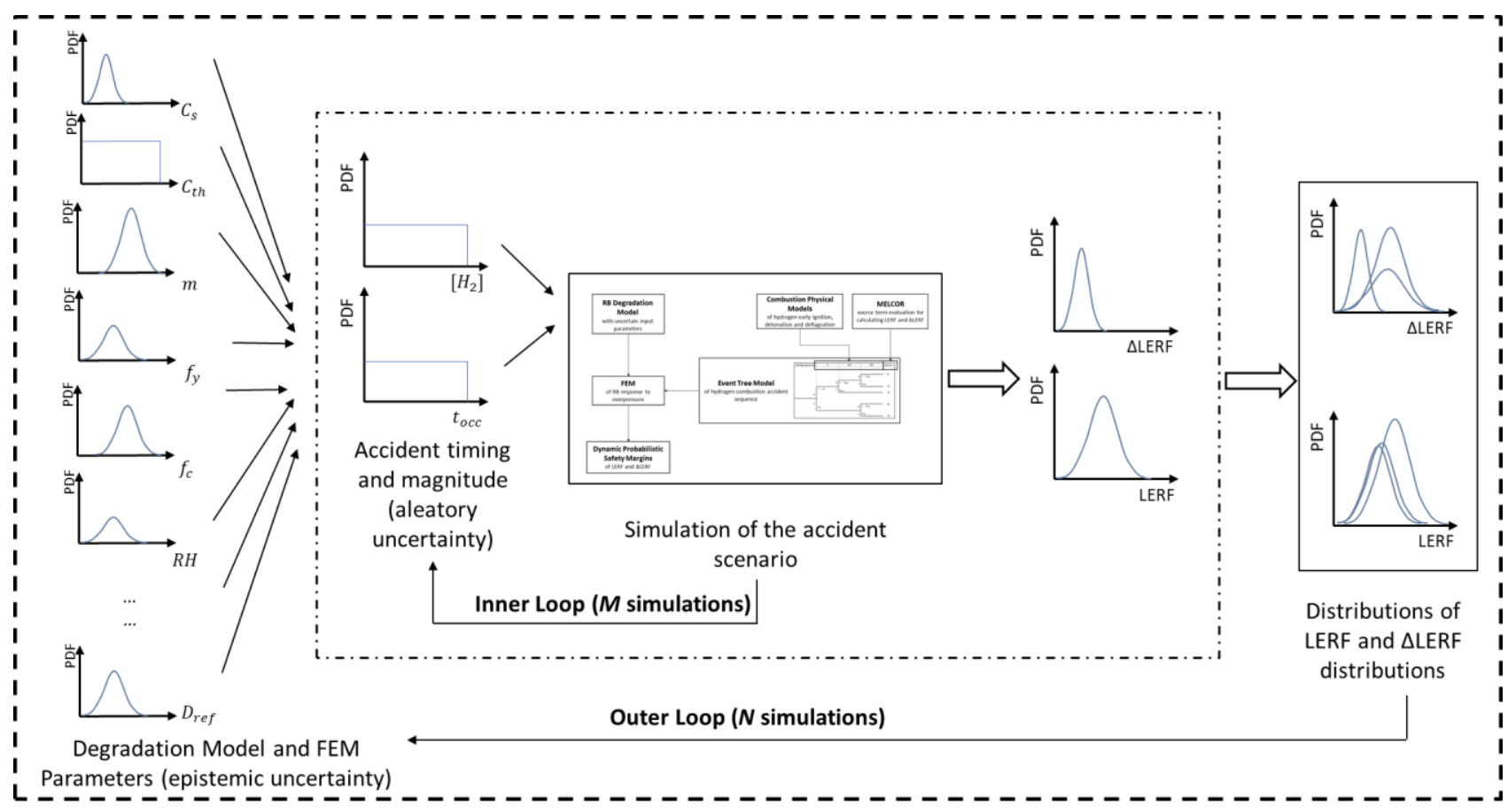

Figure 9 Double loop MC for epistemic and aleatory uncertainty propagation

Input parameters distributions are given in Table 1 and 4 (Kwon et al., 2009; Naus, 2007; Naus, Oland, Ellingwood, Graves, \& Norris, 1996).

\begin{tabular}{|c|c|c|}
\hline Parameter & Symbol & Distribution \\
\hline Occurrence time & $t_{o c c}$ & Uniform [0,100] years \\
\hline Hydrogen concentration & {$\left[\mathrm{H}_{2}\right]$} & Uniform [0,100]\% \\
\hline
\end{tabular}

Table 4 Aleatory uncertainty distributions

The procedure for probabilistic safety margin quantification by the Coverage OS approach is summarized as follows (Durga Rao et al., 2007): 
1) Set the optimal number $N$ of code runs to estimate $\hat{y}_{\gamma 1}$ and $\hat{y}_{\gamma 2}$ with confidence $\beta_{1}$ and $\beta_{2}$ as in (Nutt \& Wallis, 2004);

2) Sample the $n$-th set of epistemic variables (i.e., degradation model parameters and construction materials properties) from the probability distributions listed in Table 1;

3) Sample the $m$-th realization of the aleatory variables (i.e., hydrogen combustion accident timing and magnitude) from the distributions listed in Table 4

4) Repeat $M$ times Steps 2) and 3) to simulate the RB behavior with the dynamic reliability analysis approach described in Section 5;

5) Estimate $\hat{y}_{\gamma 1}$ and $\hat{y}_{\gamma 2}$ of the distribution of the $\gamma$ percentiles due to epistemic uncertainty as in (Nutt \& Wallis, 2004);

6) Calculate the probabilistic safety margin $M\left(\gamma_{1}, \beta_{1}, \gamma_{2}, \beta_{2}\right)$ as in Equation (23).

\section{Results}

Each curve of Figure 0 represents the fragility curves (i.e., $P_{f}(t)$ vs $\left[H_{2}\right]$ ) for the RB that does not degrade (bold stars) or degrades in time (10-100 years) as described in Section 3, resulting in larger $P_{f}(t)$ for aged $\mathrm{RB}$, for any fixed $\left[\mathrm{H}_{2}\right]$. 


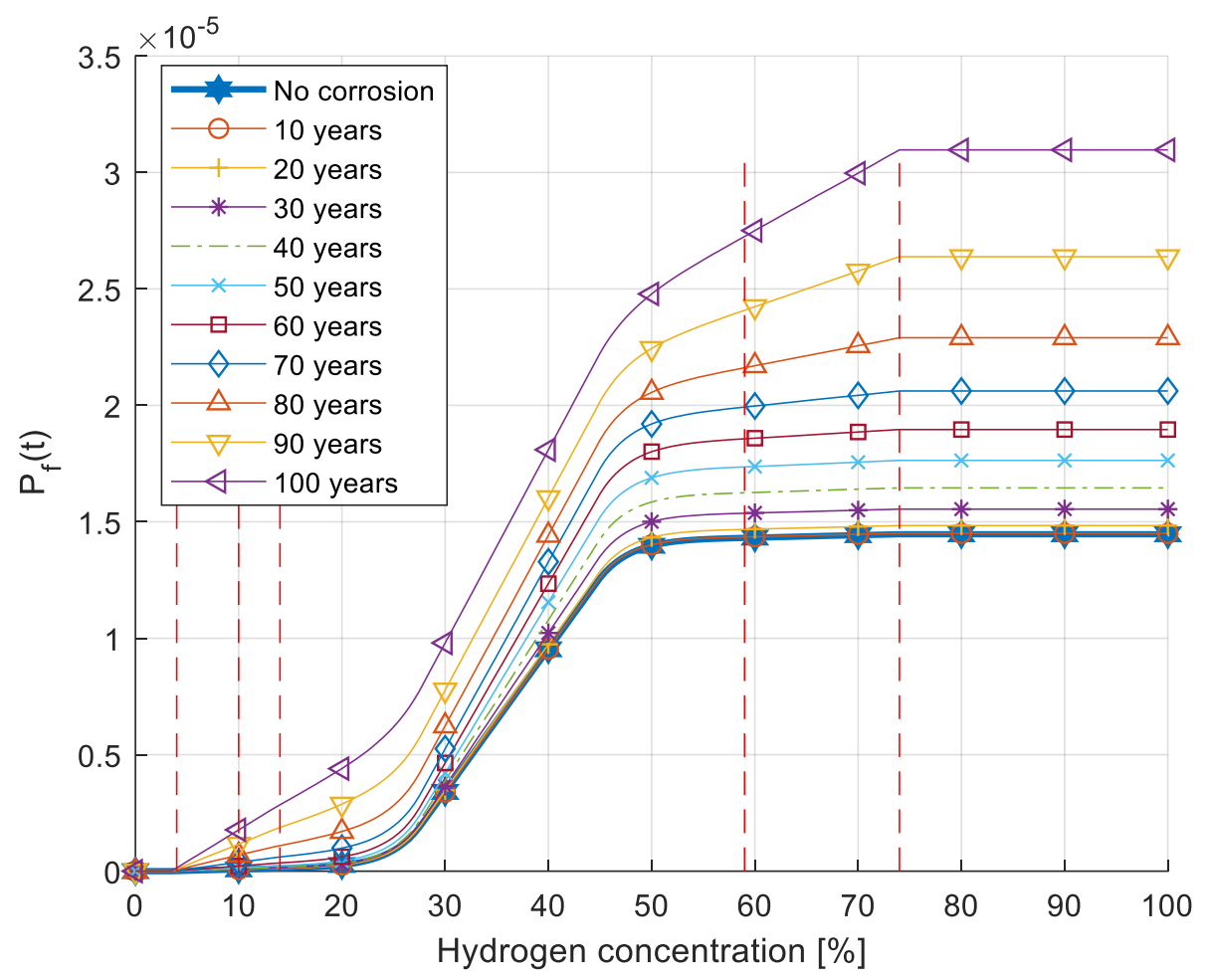

Figure 10 Fragility curve in time

It can be seen that:

1) The different overpressures generated by different combustion regimes are easily identifiable in the different ranges of hydrogen concentration (vertical dashed lines refer to the different combustion modes listed in Table 2); it can be seen that detonation range [14\%;59\%] is more likely to lead to large overpressure, making $P_{f}(t)$ grow faster than for any other combustion mode.

2) The effect of degradation worsens the RB resistance faster for older RBs: indeed, as shown in Figure 1, the overlap region between the load distribution and the resistance distribution increases as $t$ increases, meaning that the failure probability $P_{f}(t)$ increases. 

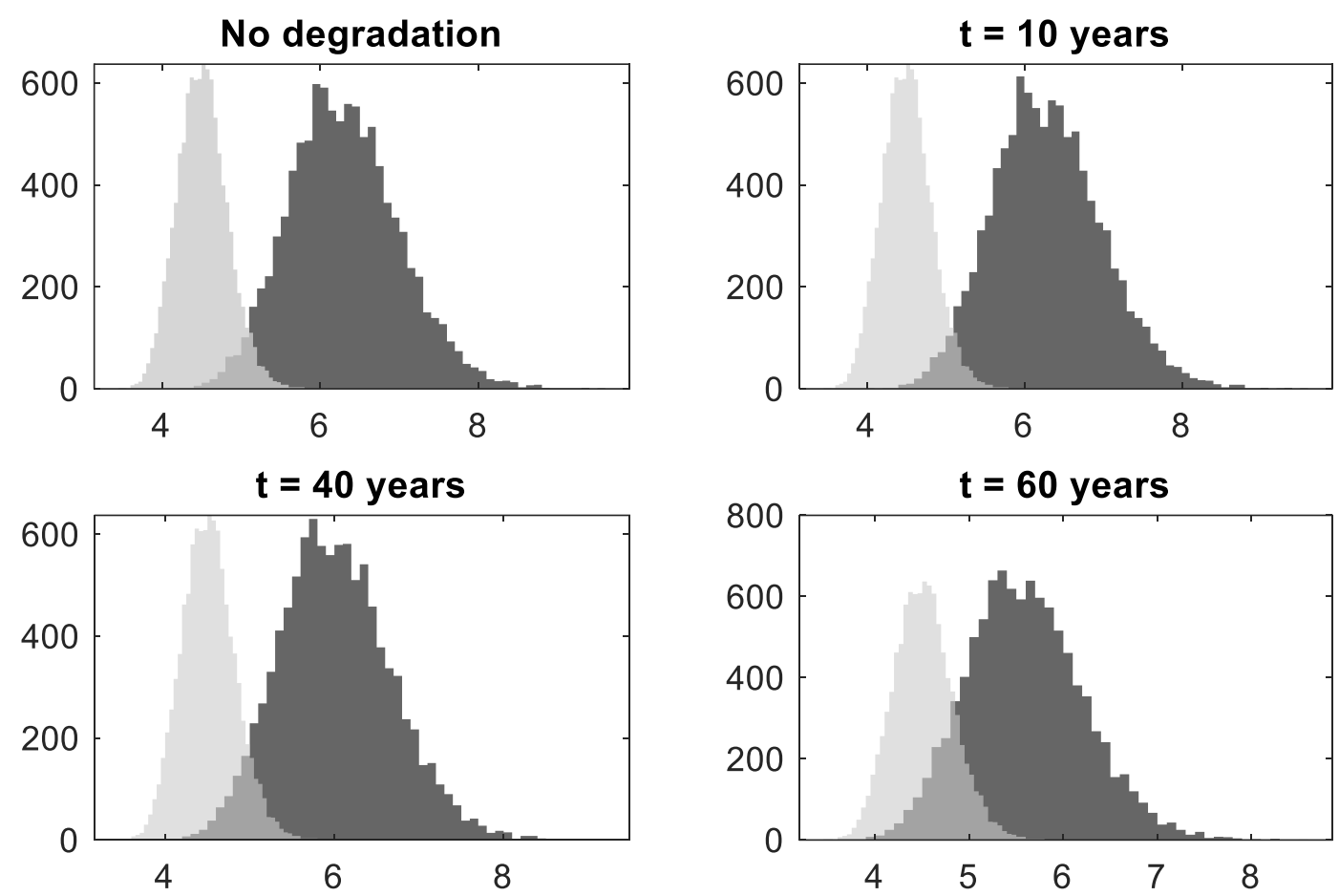

Figure 11 Capacity distribution (dark) and load distribution (light) comparison for different RB ages

Figure 22 shows the $\hat{y}_{\gamma_{1}}$ and $\hat{y}_{\gamma_{2}}\left(\gamma_{1}=\gamma_{2}=95\right)$ values obtained for different NPP ages $(10-100$ years) (dots) and their uncertainty bounds (ellipses that define the pairs of iso-probability values for LERF and $\triangle \mathrm{LERF}$, with confidence $\beta_{1}=\beta_{2}=95 \%$ ), and plotted against NRC criteria LERF $\triangle \mathrm{LERF}$ plane; if the increase in LERF $(\triangle \mathrm{LERF})$ upon $\mathrm{RB}$ resistance change exceeds $10^{-6}$ (i.e. it falls within Region I), the change is not allowed; when $\triangle$ LERF lies in the range between $10^{-7}$ and $10^{-6}$ (i.e. it lies in Region II), the change is considered acceptable only if it can be reasonably shown that the total LERF is less than $10^{-5}$; finally, if $\triangle \mathrm{LERF}$ is less than $10^{-7}$ (i.e. it falls in Region III), the change is accepted. 


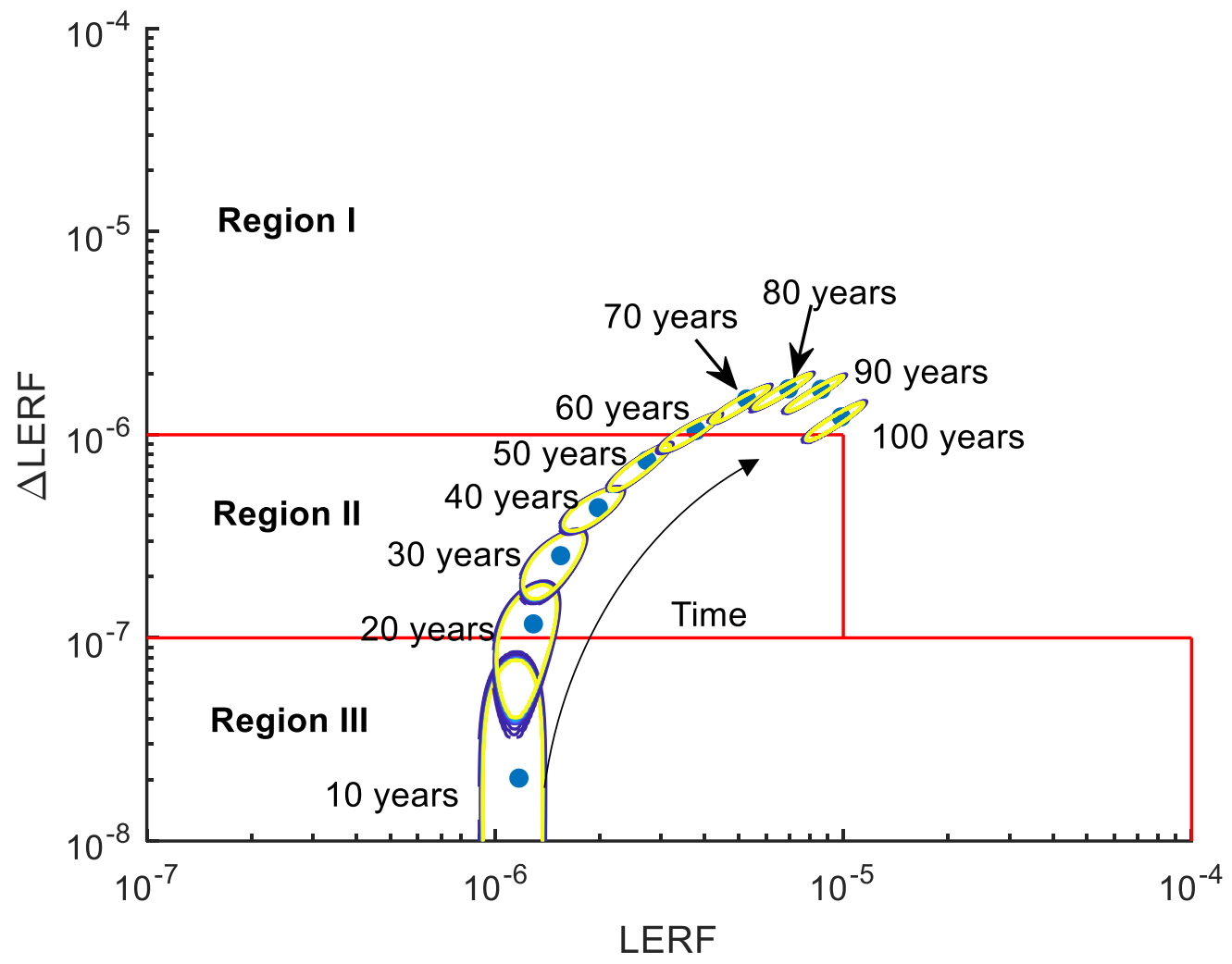

Figure 22 NRC acceptance criteria for LERF. Each dot represents the pair LERF and $\triangle L E R F$, evaluated at 10 years interval; ellipses indicate uncertainty bounds

The dynamic reliability analysis approach here developed allows describing the time evolution of LERF and $\triangle \mathrm{LERF}$ due to the degradation of the RB. The degradation due to aging can lead to unacceptable conditions, starting from $t>60$ years, if no maintenance activity is undertaken to counteract the degradation processes. Indeed, for $U_{1}=\left\{\begin{array}{l}10^{-4} \text { if } y_{2}<10^{-7} \\ 10^{-5} \text { if } y_{2}>10^{-7}\end{array}, U_{2}=10^{-6}, y_{1, \text { ref }}=\right.$ $1.4 \cdot 10^{-6}, y_{2, \text { ref }}=0$ the results of Table 5 are collected. This result confirms the necessity of maintaining the RB within 60 years, as it is currently done in the nuclear industry, where modeling the RB deterioration and repair is state-of-practice. The added value of the result shown in Figure 12 is that it allows providing actualized estimates of risk measures and probabilistic safety margins, as degradation progresses with time: this information is useful for decision-makers to decide when to perform RB maintenance. For example, one might decide to never accept exceeding Region III or Region II and, correspondingly, proceed conservatively to maintain the RB no more than each 10 
years, or 50 years, respectively, as suggested by the estimates of the percentiles $\hat{y}_{\gamma_{2}}$ and the associated probabilistic safety margins $M\left(\gamma_{2}=0.95, \beta_{2}=0.95\right)$ for LERF and $\triangle \mathrm{LERF}$ at the different NPP ages 10-100 years, shown in Table 5. On the other hand, one might rely on the estimates of the percentiles $\hat{y}_{\gamma_{1}}$ and the associated probabilistic safety margins $M\left(\gamma_{1}=0.05, \beta_{1}=0.95\right)$ to decide with less conservativism to maintain the RB even between 70 and 80 years (after which $M=0$ ).

\begin{tabular}{|c|c|c|c|c|}
\hline \multirow[t]{2}{*}{ Time } & \multicolumn{2}{|c|}{ LERF } & \multicolumn{2}{|c|}{$\Delta \mathbf{L E R F}$} \\
\hline & $\begin{array}{l}\text { Percentile } \\
\qquad \hat{y}_{\gamma_{1}}\end{array}$ & $\begin{array}{c}\text { Margin } \\
M\end{array}$ & $\begin{array}{l}\text { Percentile } \\
\qquad \hat{y}_{\gamma_{2}}\end{array}$ & $\begin{array}{c}\text { Margin } \\
\quad M\end{array}$ \\
\hline 0 & $7.0387 \mathrm{e}-07$ & 0.9390 & I & I \\
\hline 10 & $1.4422 \mathrm{e}-6$ & 0.8644 & $7.1578 \mathrm{e}-08$ & 1 \\
\hline 20 & $1.5930 \mathrm{e}-6$ & 0.8491 & $1.3545 \mathrm{e}-07$ & 0.8732 \\
\hline 30 & $1.8899 \mathrm{e}-6$ & 0.8192 & $2.9251 \mathrm{e}-07$ & 0.7146 \\
\hline 40 & $2.4458 \mathrm{e}-6$ & 0.7617 & $5.3181 \mathrm{e}-07$ & 0.4729 \\
\hline 50 & $3.3476 \mathrm{e}-6$ & 0.6719 & $8.4190 \mathrm{e}-07$ & 0.1596 \\
\hline 60 & $4.6743 \mathrm{e}-6$ & 0.5379 & $1.2893 \mathrm{e}-06$ & 0 \\
\hline 70 & $6.5009 \mathrm{e}-06$ & 0.3534 & $1.7299 \mathrm{e}-06$ & 0 \\
\hline 80 & $8.5916 \mathrm{e}-06$ & 0.1422 & $2.0129 \mathrm{e}-06$ & 0 \\
\hline 90 & $1.0652 \mathrm{e}-05$ & 0 & $1.9691 \mathrm{e}-06$ & 0 \\
\hline 100 & $1.2151 \mathrm{e}-05$ & 0 & $1.4361 \mathrm{e}-06$ & 0 \\
\hline
\end{tabular}

Table 5 LERF and $\triangle L E R F$ percentile estimates and probabilistic safety margin 


\section{Conclusions}

In recent years, in light of the international concern on the safety of nuclear facilities, the assessment of the conditions of aging RC RBs has become a focal point of attention to guarantee containment of radioactivities. In this work, we have proposed a dynamic reliability analysis framework and applied it to evaluate the resistance of the RB of a BWR Mark I to a hydrogen combustion accident scenario, while accounting for the effects of aging and degradation of the reinforced concrete.

Monte Carlo is adopted to duly account for both epistemic and aleatory uncertainty, whereas a FEM of the RB has been built to analyze how the structure reacts to an internal overpressure and a physicsbased model of chlorides-induced corrosion of steel reinforcement and concrete cracking is employed to update the resistance of the $\mathrm{RB}$, and the resulting time-dependent fragility curve to reflect how the failure probability increases in time due to aging effects: resorting to Order Statistics, the percentiles of the distributions of the safety parameters (i.e., LERF and $\triangle \mathrm{LERF}$ ) are estimated. In the case study considered, given the assumptions made, the comparison of the updated LERF and $\triangle$ LERF with the NRC requirements shows that, without any maintenance activity, the risk may become unacceptable to the purpose of license renewal.

The main advancement of the framework here proposed consists in the capability of providing actualized estimates of risk measures and probabilistic safety margins, as degradation progresses with time.

On the other hand, the main limitation is that the actualized estimates are not informed about the actual state of the RC structure (i.e., any condition monitoring system gathering data from sensors is neglected), but the estimates are provided on the basis of only simulated data (as the NPP RB degrades). Therefore, future work will consider embedding of condition monitoring data within the dynamic reliability framework for actualizing the risk measures and safety margins, based on degradation evidence measured directly on the RB. 


\section{Acknowledgment}

The work is developed within the research project "SMART MAINTENANCE OF INDUSTRIAL PLANTS AND CIVIL STRUCTURES BY 4.0 MONITORING TECHNOLOGIES AND PROGNOSTIC APPROACHES - MAC4PRO ", sponsored by the call BRIC-2018 of the National Institute for Insurance against Accidents at Work - INAIL.

\section{References}

(Aldemir, 2013) Aldemir, T., A survey of dynamic methodologies for probabilistic safety assessment of nuclear power plants, Annals of Nuclear Energy, 52, 113-124, 2013.

(Aldemir, 2018) Aldemir, T., Advanced Concepts in Nuclear Energy Risk Assessment and Management. WORLD SCIENTIFIC, 2018.

(Camp, Cummings, Sherman, Kupiec, Healy, Caplan, ... Saunders, 1983) Camp, A. L., Cummings, J. C., Sherman, M. P., Kupiec, C. F., Healy, R. J., Caplan, J. S., ... Saunders, J. H., Light Water Reactor Hydrogen Manual, 1983.

(Coronelli \& Gambarova, 2004) Coronelli, D., \& Gambarova, P., Structural Assessment of Corroded Reinforced Concrete Beams: Modeling Guidelines, Journal of Structural Engineering, 130(8), 1214-1224, 2004.

(Coyne \& Mosleh, 2018) Coyne, K., \& Mosleh, A., Dynamic Probabilistic Risk Assessment Model Validation and Application - Experience with ADS-IDAC, Version 2.0, In Advanced Concepts in Nuclear Energy Risk Assessment and Management (pp. 45-85), 2018.

(Devooght, 1997) Devooght, J., Dynamic reliability, Advances in Nuclear Science and Technology, $25,215-278,1997$. 
(Di Maio, Baronchelli, Vagnoli, \& Zio, 2017) Di Maio, F., Baronchelli, S., Vagnoli, M., \& Zio, E., Determination of prime implicants by differential evolution for the dynamic reliability analysis of non-coherent nuclear systems, Annals of Nuclear Energy, 102, 91-105, 2017.

(Di Maio, Picoco, Zio, \& Rychkov, 2017) Di Maio, F., Picoco, C., Zio, E., \& Rychkov, V., Safety margin sensitivity analysis for model selection in nuclear power plant probabilistic safety assessment, Reliability Engineering and System Safety, 162(February), 122-138, 2017.

(Di Maio, Rai, \& Zio, 2016) Di Maio, F., Rai, A., \& Zio, E., A dynamic probabilistic safety margin characterization approach in support of Integrated Deterministic and Probabilistic Safety Analysis, Reliability Engineering and System Safety, 145, 9-18, 2016.

(Durga et al., 2011) Durga, R. K,, Dang, V. N., Kim, T.W., Discrete dynamic event tree analysis of mloca using ads-trace, NS PSA 2011 International Topical Meeting on Probabilistic Safety Assessment and Analysis, 2011

(Du, Clark, \& Chan, 2005) Du, Y. G., Clark, L. A., \& Chan, A. H. C., Residual capacity of corroded reinforcing bars, Magazine of Concrete Research, 57(3), 135-147, 2005.

(Durga Rao, Kushwaha, Verma, \& Srividya, 2007) Durga Rao, K., Kushwaha, H. S., Verma, A. K., \& Srividya, A., Quantification of epistemic and aleatory uncertainties in level-1 probabilistic safety assessment studies, Reliability Engineering \& System Safety, 92(7), 947-956, 2007.

(El Hassan, Bressolette, Chateauneuf, \& El Tawil, 2010) El Hassan, J., Bressolette, P., Chateauneuf, A., \& El Tawil, K., Reliability-based assessment of the effect of climatic conditions on the corrosion of RC structures subject to chloride ingress, Engineering Structures, 32(10), 3279$3287,2010$.

(Fernández-Cosials et al., 2017) Fernández-Cosials, K., Jimenez, G., Bocanegra, R., Queral, C., Study of hydrogen risk in a PWR-W containment during a SBO scenario; Tau parameter definition and 
application on venting strategy analysis, Nuclear Engineering and Design, Volume 325, 15 December 2017, Pages 164-177.

(Hakobyan et al., 2008) Hakobyan, A. et al., Dynamic generation of accident progression event trees, Nucl. Eng. Des. 238, 3457-3467, 2008.

(Helton, 1998) Helton J.C. et al., Uncertainty and sensitivity analysis results obtained in the 1996 performance assessment for the waste isolation pilot plant. SAND98-0365. Sandia National Laboratories, 1998.

(Helton, 2009) Helton, J. C., Conceptual and computational basis for the quantification of margins and uncertainty., Reliability Engineering and System Safety, 2009.

(Helton, 2011) Helton, J. C., Quantification of margins and uncertainties: Conceptual and computational basis, Reliability Engineering and System Safety, 96(9), 976-1013, 2011.

(IAEA, 1994) IAEA, Advances in Reliability Analysis and Probabilistic Safety Assessment for Nuclear Power Reactors, IAEA-TECDOC-737, 1994.

(Izquierdo et al., 2009) Izquierdo, J.M., Hortal, J., Sánchez-Perea, M., Meléndez, E., Herrero, R., Gil, J., Fernández, I., Mundina, J., Rodríguez-Martín, G., Cañamón, I., Queral, C., Expósito, A., Ibáñez, L., Elorza, F.J., Ibáñez, C., Nieto, F., Pilot applications of the integrated safety assessment methodology, International Congress on Advances in Nuclear Power Plants 2009, ICAPP 2009; Shinjuku, Tokyo; Japan; 10 May 2009 through 14 May 2009; Code 108003.

(Kuznetsov, Yanez, Grune, Friedrich, \& Jordan, 2015) Kuznetsov, M., Yanez, J., Grune, J., Friedrich, A., \& Jordan, T., Hydrogen combustion in a flat semi-confined layer with respect to the Fukushima Daiichi accident, Nuclear Engineering and Design, 286(January), 36-48, 2015. 
(Kloss et al., 2002) Kloos M. et al. (2002), "Analysis of epistemic and aleatory uncertainties in the context of a dynamic fire-PSA", 6th International Conference on Probabilistic Safety Assessment and Management, Conference Proceedings 23 - 28 June 2002, San Juan, Puerto Rico, USA.

(Kloos et al., 2006) Kloos, M., Peschke, J., MCDET: A Probabilistic Dynamics Method Combining Monte Carlo Simulation with the Discrete Dynamic Event Tree Approach, Nuclear Science and Engineering Volume 153, 2006 - Issue 2, 2006.

(Kwon, Na, Park, \& Jung, 2009) Kwon, S. J., Na, U. J., Park, S. S., \& Jung, S. H., Service life prediction of concrete wharves with early-aged crack: Probabilistic approach for chloride diffusion, Structural Safety, 31(1), 75-83, 2009.

(Labeau, Smidts, \& Swaminathan, 2000) Labeau, P. E., Smidts, C., \& Swaminathan, S., Dynamic reliability: towards an integrated platform for probabilistic risk assessment, Reliability Engineering \& System Safety, 68(3), 219-254, 2000.

(Liu \& Weyers, 1998) Liu, T., \& Weyers, R. W., Modeling the dynamic corrosion process in chloride contaminated concrete structures, Cement and Concrete Research, 28(3), 365-379, 1998.

(Luping \& Gulikers, 2007) Luping, T., \& Gulikers, J., On the mathematics of time-dependent apparent chloride diffusion coefficient in concrete, Cement and Concrete Research, 37(4), 589$595,2007$.

(Martorell, Nebot, F Vilanueva, Carlos, Serradell, Pelayo, \& Mendizabal, 2006) Martorell, S., Nebot, Y., F Vilanueva, J., Carlos, S., Serradell, V., Pelayo, F., \& Mendizabal, R., Safety margins estimation method considering uncertainties within the risk- informed decision-making framework, In Proceedings of the PHYSOR 2006 conference. Vancouver, Canada, 2006.

(Martorell, Nebot, Villanueva, Carlos, Serradell, Pelayo, \& Mendizabal, 2009) Martorell, S., Nebot, 
Y., Villanueva, J., Carlos, S., Serradell, V., Pelayo, F., \& Mendizabal, R., An approach to integrate thermal-hydraulic and probabilistic analyses in addressing safety margins estimation accounting for uncertainties. Safety, reliability and risk analysis: theory, methods and applications, In Proceedings of the Joint ESREL and SRA-Europe conference (Vol. 4, pp. 28272835), 2009.

(Melchers \& Beck, 2018) Melchers, R. E., \& Beck, A. T., Structural Reliability Analysis and Prediction. John Wiley \& Sons, 2018.

(Mercurio, Andersen, \& Wagner, 2017) Mercurio, D., Andersen, V. M., \& Wagner, K. C., Integrated level 1-level 2 decommissioning probabilistic safety assessment methodology for boiling water reactors, In Safety and Reliability - Theory and Applications - Proceedings of the 27th European Safety and Reliability Conference, ESREL 2017 (Vol. 50, pp. 1441-1450). Elsevier, 2017.

(Mercurio et a., 2018) D. Mercurio et al., "Integrated Level 1-Level 2 decommissioning probabilistic risk assessment for boiling water reactors", Nuclear Engineering and Technology, 50, 2018.

(Naus, 2007) Naus, D. J., Primer on Durability of Nuclear Power Plant Reinforced Concrete Structures - A Review of Pertinent Factors, NUREG/CR-6927 ORNL/TM-2006/529, 130, 2007.

(Naus, Oland, \& Ellingwood, 1996) Naus, D. J., Oland, C. B., \& Ellingwood, B. R., Report on aging of nuclear power plant reinforced concrete structures, NUREG/CR-6424 ORNL/TM-13148, 1996.

(Naus, Oland, Ellingwood, Graves, \& Norris, 1996) Naus, D. J., Oland, C. B., Ellingwood, B. R., Graves, H. L., \& Norris, W. E., Aging management of containment structures in nuclear power plants, Nuclear Engineering and Design, 166(3), 367-379, 1996.

(Nuclear Regulatory Commission, 2017) Nuclear Regulatory Commission, Generic Aging Lessons Learned for Subsequent License Renewal (GALL-SLR) Report, 2, 2017. 
(Nuclear Regulatory Commission, 2018) Nuclear Regulatory Commission, An Approach for Using Probabilistic Risk Assessment in Risk-Informed Decisions on Plant-Specific Changes to the Licensing Basis, Regulatory Guide 1.174, (January), 2018.

(NUREG/CR-2300, 1983) NUREG/CR-2300, PRA Procedure Guide, US Nuclear Regulatory Commision, 1, 1983.

(NUREG/CR-2815, 1983) NUREG/CR-2815, Probabilistic Safety Analysis Procedures Guide, Nureg/Cr-2815 Bnl-Nureg-51559, 1983.

(Nutt \& Wallis, 2004) Nutt, W. T., \& Wallis, G. B., Evaluation of nuclear safety from the outputs of computer codes in the presence of uncertainties, Reliability Engineering and System Safety, 83(1), 57-77, 2004.

(Papakonstantinou \& Shinozuka, 2013a) Papakonstantinou, K. G., \& Shinozuka, M., Probabilistic model for steel corrosion in reinforced concrete structures of large dimensions considering crack effects, Engineering Structures, 57, 306-326, 2013 a.

(Papakonstantinou \& Shinozuka, 2013b) Papakonstantinou, K. G., \& Shinozuka, M., Spatial stochastic direct and inverse analysis for the extent of damage in deteriorated RC structures, Computers and Structures, 128, 286-296, 2013b.

(Rebollo et al., 2016) Rebollo, M.J., Queral, C., Jimenez, G., Gomez-Magan, J., Meléndez, E., Sanchez-Perea, M., Evaluation of the offsite dose contribution to the global risk in a Steam Generator Tube Rupture scenario, Reliability Engineering and System Safety, Volume 147, March 2016, Pages 32-48

(Sandia National Laboratories, 2017) Sandia National Laboratories, MELCOR Computer Code Manuals, Vol.1: Primer and Users' Guide, 1(January), 2017. 
(Secchi, Zio, \& Di Maio, 2008) Secchi, P., Zio, E., \& Di Maio, F., Quantifying uncertainties in the estimation of safety parameters by using bootstrapped artificial neural networks, Annals of Nuclear Energy, 35(12), 2338-2350, 2008.

(Simulia, 2011) Simulia, D. C. S., Abaqus 6.11 analysis user's manual, Abaqus 6.11 Documentation, 22, 2011.

(Stewart, 2009) Stewart, M. G., Mechanical behaviour of pitting corrosion of flexural and shear reinforcement and its effect on structural reliability of corroding RC beams, Structural Safety, 31(1), 19-30, 2009.

(Stewart \& Rosowsky, 1998) Stewart, M. G., \& Rosowsky, D. V., Time-dependent reliability of deteriorating reinforced concrete bridge decks, Structural Safety, 20(1), 91-109, 1998.

(Thoft-Christensen \& Beck, 1982) Thoft-Christensen, P., \& Beck, A. T., Structural Reliability Theory and Its Applications. Springer - Verlag, 1982.

(Tuutti, 1982) Tuutti, K., Corrosion of steel in concrete. Swedish Cement and Concrete Research Institute, 1982.

(Vu \& Stewart, 2000) Vu, K. A. T., \& Stewart, M. G., Structural reliability of concrete bridges including improved chloride-induced corrosion models, Structural Safety, 22(4), 313-333, 2000.

(Wald, 1943) Wald A., An extension of Wilks method for setting tolerance limits. Ann Math Stat $1943 ; 14(1): 45-55$.

(Wakefield, Budniz, \& Kiper, 2014) Wakefield, D. J., Budniz, R. J., \& Kiper, K. L., Requirements for Low Power and Shutdown Probabilistic Safety Assessment, ANS/ASME-58.22. ASME, 2014.

(Zio, 2014) Zio, E., Integrated deterministic and probabilistic safety assessment: Concepts, 
challenges, research directions, Nuclear Engineering and Design, 280, 413-419, 2014.

(Zio \& Di Maio, 2008) Zio, E., \& Di Maio, F., Bootstrap and Order Statistics for Quantifying Thermal-Hydraulic Code Uncertainties in the Estimation of Safety Margins, Science and Technology of Nuclear Installations, 2008, 1-9, 2008. 